\title{
Design, synthesis, anti-HIV evaluation and molecular modeling of piperidine-linked amino-triazine derivatives as potent non-nucleoside reverse transcriptase inhibitors
}

\author{
Xuwang Chen ${ }^{\mathrm{a}}$, Peng Zhan ${ }^{\mathrm{a}}$, Xin Liu ${ }^{\mathrm{a}}$, Ziheng Cheng ${ }^{\mathrm{b}}$, Caicai Meng ${ }^{\mathrm{a}}$, Siyuan Shao ${ }^{\mathrm{a}}$, \\ Christophe Pannecouque ${ }^{c}$, Erik De Clercq ${ }^{c}$, Xinyong Liu ${ }^{\mathrm{a}, *}$ \\ ${ }^{a}$ Department of Medicinal Chemistry, School of Pharmaceutical Sciences, Shandong University, 44, West Culture Road, 250012 Ji'nan, Shandong, PR China \\ ${ }^{\mathrm{b}}$ Marine College, Shandong University, Weihai Wenhua West Road, No. 180, Weihai 264209, Shandong, PR China \\ ${ }^{\mathrm{c}}$ Rega Institute for Medical Research, K.U. Leuven, Minderbroedersstraat 10, B-3000 Leuven, Belgium
}

\section{A R T I C L E I N F O}

\section{Article history:}

Received 5 March 2012

Revised 11 April 2012

Accepted 16 April 2012

Available online 21 April 2012

\section{Keywords:}

HIV-1

NNRTIs

Piperidine

Triazine

Antiviral activity

SAR

Molecular modeling

\begin{abstract}
A B S T R A C T
A novel series of piperidine-linked amino-triazine derivatives were designed, synthesized and evaluated for in vitro anti-HIV activity as non-nucleoside reverse transcriptase inhibitors on the basis of our previous work. Screening results indicated that most compounds showed excellent activity against wild-type HIV-1 with $\mathrm{EC}_{50}$ values in low nanomolar concentration range (especially compound $\mathbf{6 b} 3, \mathrm{EC}_{50}=4.61 \mathrm{nM}$, $\mathrm{SI}=5945)$ and high activity against $\mathrm{K} 103 \mathrm{~N} / \mathrm{Y} 181 \mathrm{C}$ resistant mutant strain of HIV-1 with $\mathrm{EC}_{50}$ values in low micromolar concentration range. In addition, preliminary structure-activity relationship and molecular modeling of these new analogs were detailed in this manuscript.
\end{abstract}

Crown Copyright $\odot 2012$ Published by Elsevier Ltd. All rights reserved.

\section{Introduction}

Acquired immune deficiency syndrome (AIDS) mainly caused by human immunodeficiency virus type-1 (HIV-1), is one of the leading pandemic diseases worldwide. Because of the lack of vaccine, the highly active antiretroviral therapy (HAART) regimen plays a crucial role in the treatment of HIV-1 infection, however, drug resistance and side effects often compromise clinical treatment. ${ }^{1} \mathrm{HIV}-1$ non-nucleoside reverse transcriptase inhibitors (HIV-1 NNRTIs) have become an indispensable component of HAART, with unique antiviral potency, high specificity and low cytotoxicity. ${ }^{2}$ Especially, diarylpyrimidine (DAPY) derivatives, such as Dapivirine (TMC120), Etravirine (TMC125, ETV) and Rilpivirine (TMC278) showed highly potent activity against wild-type and NNRTI-resistant strains of HIV-1 (Fig. 1), ${ }^{3,4}$ of which, TMC125 and TMC278 have been approved by FDA, providing an additional treatment option for HAART regimen. Further research of DAPY derivatives was focused on diverse structural modifications, including the left wing, ${ }^{5-7}$ the linker between the left benzene ring and the central pyrimidine ring, $^{8-10}$ the central pyrimidine core ${ }^{11-14}$ and the right wing. ${ }^{15,16}$

\footnotetext{
* Corresponding author. Tel.: +86 531 88380270; fax: +86 53188382731.

E-mail address: xinyongl@sdu.edu.cn (X. Liu).
}

Among these structurally modified analogs, piperidine-linked aminopyrimidine derivatives (Fig. 2) displayed promising potency against wild-type and several important resistant mutant strains of HIV-1, as well as enhanced water solubility to potentially meliorate the pharmacokinetic profile, which make it extensive concern in DAPY analogs.

Recently, we designed and synthesized a novel series of DAPY analogs with piperidine-substituted triazine moiety, which are structurally similar to the piperidine-linked aminopyrimidine derivatives. From biological assay, we had discovered some new lead compounds to be potent and selective HIV-1 NNRTIs with $\mathrm{IC}_{50}$ values at nanomoles ranges. ${ }^{17}$ Encouraged by this result and continued to pursue our studies, we undertook a new round of structural modification of piperidine-substituted triazine derivatives, in which, amino group was introduced to the triazine ring, similar to that observed in the structure of Etravirine (Fig. 2), which may improve hydrogen bond interaction with amino acid residues inside the binding pocket of HIV-1 NNRT. ${ }^{18}$ In addition, polar hydrophilic substituents and heterocycle were introduced to the right wing (Fig. 2) that is oriented directly into the exterior water through a rather small opening window in the protein/solvent interface, which is thought to be playing an important role in the capacity to inhibit HIV-1 replication and improve pharmaco- 


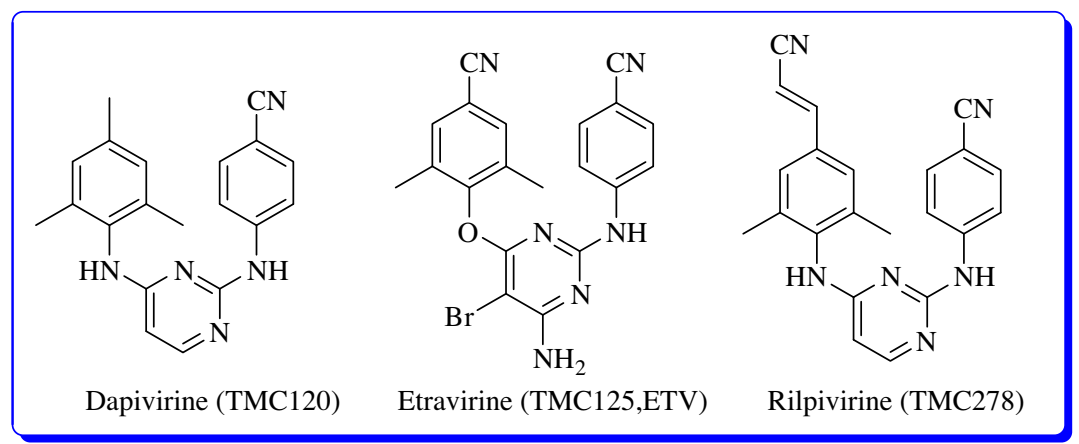

Figure 1. The structures of DAPY derivatives.

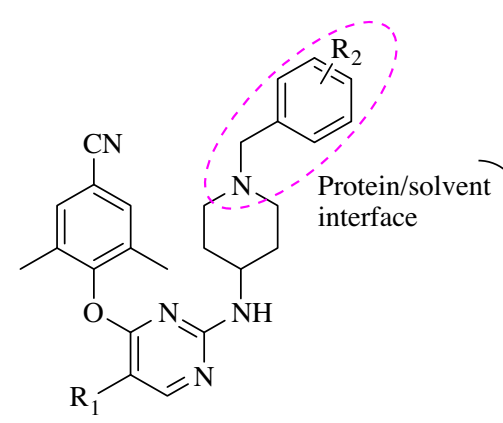

Piperidine-linkedaminopyrimidines

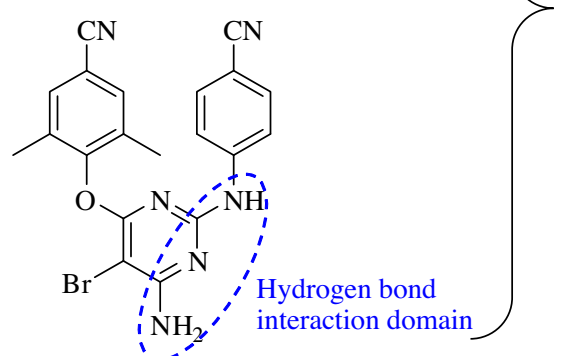

Approved drúg by FDA

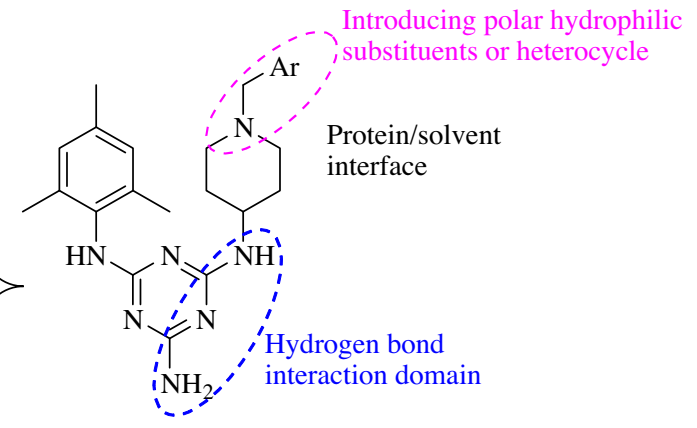

Newly designed compounds

Figure 2. The design of piperidine-linked amino-triazine derivatives.

kinetic properties. ${ }^{19}$ Herein, we will detailedly report the synthesis, anti-HIV evaluation, preliminary structure-activity relationship (SAR) and molecular modeling of the newly designed piperidinelinked amino-triazine analogs.

\section{Results and discussion}

\subsection{Chemistry}

The synthesis route of the target compounds 6a1-6a8, 6b1-6b5 and 6c1-6c5 was shown in Scheme 1. The intermediate 6-chloro$N^{2}$-mesityl- $N^{4}$-(1-Boc-piperidin-4-yl)-1,3,5-triazine-2,4-diamine (3) was prepared from structurally symmetrical 2,4,6-trichloro-1,3, 5-triazine (1) by substitution reaction with 2,4,6-trimethylaniline and 4-amino-1-Boc-piperidine successively in mild reaction conditions. ${ }^{20}$ Treatment of intermediate 3 with ammonia under high temperature in sealed reactor, ${ }^{21}$ aqueous methylamine and sodium methoxide gave the intermediate $\mathbf{4 a}, \mathbf{4 b}$ and $\mathbf{4 c}$, respectively. ${ }^{22}$ Boc group was removed in the presence of trifluoroacetic acid (TFA) at room temperature to afford $\mathbf{5 a}, \mathbf{5 b}$ and $\mathbf{5 c}$, which were alkylated at the $\mathrm{N}$ atom of piperidine, achieving the final compounds 6a1-6a8, 6b1-6b5 and 6c1-6c5, respectively. Both analytical and spectral data of all the compounds are in full agreement with the proposed structures.

\subsection{Biological activity}

The newly synthesized piperidine-linked amino-triazine derivatives were tested for their anti-HIV activity and cytotoxicity in MT4 cells infected by wild-type HIV-1 (IIIB) and the double mutant strains RES056 (K103N+Y181C) along with HIV-2 (ROD) according to the MTT method reported previously. ${ }^{17,23-25}$ FDA-approved drugs: Nevirapine (NVP), Delavirdine Mesylate (DLV), Efavirenz (EFV), Zidovudine (Azidothymidine, AZT), Dideoxycitidine (DDC) and Etravirine (ETV) ${ }^{26}$ were used as reference drugs. The biological evaluation results were interpreted in $\mathrm{EC}_{50}$ (anti-HIV activity), $\mathrm{CC}_{50}$ values (cytotoxicity) and SI (selectivity index, given by the $\mathrm{CC}_{50} /$ $\mathrm{EC}_{50}$ ratio) as shown in Tables 1 and 2.

As listed in Table 1, most compounds showed high activity against wild-type HIV-1 with $\mathrm{EC}_{50}$ values in the range of 4.61$20.43 \mathrm{nM}$ and high SI values ranging from 297 to 5945 . Compound 6b3 was the most potent compound $\left(\mathrm{EC}_{50}=4.61 \mathrm{nM}, \mathrm{SI}=5945\right)$, superior to the reference drugs NVP, DLV, EFV, AZT and DDC, but a little inferior to ETV against wild-type HIV-1. Introduction of $\mathrm{NH}_{2}$ at the triazine ring (6a1-6a5) improved the activity compared to the -NHMe series (6b1-6b5) and-OMe series (6c1-6c5) except the compound with 4-carbamoylphenyl group (6a3). Compared to compound 6a6, compounds 6a4, 6a5, 6a7 and $6 \mathbf{a} 8$ showed more potent activity due to the presences of polar hydrophilic substitu- 
<smiles>Clc1nc(Cl)nc(Cl)n1</smiles>

1<smiles>Cc1cc(C)c(Nc2nc(Cl)nc(Cl)n2)c(C)c1</smiles>

2<smiles>Cc1cc(C)c(Nc2nc(Cl)nc(NC3CCN(C(=O)c4ccccc4)CC3)n2)c(C)c1</smiles>

3<smiles>[R]c1nc(Nc2c(C)cc(C)cc2C)nc(NC2CCNCC2)n1</smiles>

5a, $\mathrm{R}=\mathrm{NH}_{2}$

5b, R = NHMe

5c, $\mathrm{R}=\mathrm{OMe}$<smiles>[R]c1nc(Nc2c(C)cc(C)cc2C)nc(NC2CCN(C(=O)OC(C)(C)C)CC2)n1</smiles>

4a, $\mathrm{R}=\mathrm{NH}_{2}$ 4b, $\mathrm{R}=\mathrm{NHMe}$ $4 c, \mathrm{R}=\mathrm{OMe}$

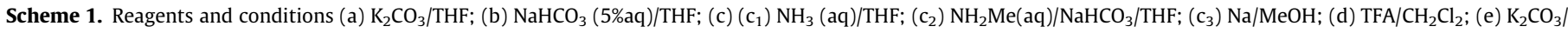
DMF.

ents at the para phenyl, such as sulfamoyl, methylsulfonyl, cyano and nitro groups. Additionally, substitution of phenyl group (6a6) with polar hydrophilic pyridyl group (6a1) was confirmed contributing to the anti-HIV-1 activity. Among the tested compounds, compounds $\mathbf{6 a 2}, \mathbf{6 b 2}$ and $\mathbf{6 c 2}$ with 4-COOEt-Ph displayed reduced potency against wild-type HIV-1 and increased cytotoxicity with lower SI values, because the ethyl group is hydrophobic and could not extend into the exterior water of the opening RT pocket.

In summary, introduction of $-\mathrm{NH}_{2}$ at the triazine ring and polar hydrophilic groups at the right wing were favorable to improvement of activity against wild-type HIV-1 indeed. Furthermore, none of the newly synthesized compounds were active at subtoxic concentration against HIV-2 (ROD) in MT-4 cells.

In the treatment of HIV-1 infection, drug resistance is still a key cause of failure for their antiviral efficacy. There are many resistant RT mutations of HIV-1, such as L100I, K101E, K103N, V106A, V179F, Y181C, Y188L, G190A, F227C, L234I and Y318F. Among them, K103N and Y181C resistant mutant strains are the most often encountered mutations in the treatment of AIDS with HIV-1 NNRTIs clinically. ${ }^{27}$ With the aim to define the resistance profiles of these compounds, they were also assayed against the K103N/Y181C resistant mutant strain of HIV-1 with the results illustrated in Table 2. As the data indicated, both the absolute activity against the HIV-1 mutants ( $\mathrm{EC}_{50}$ values) and the relative activity (fold resistance) needed to be taken into consideration of the potency. Most compounds displayed high activity against K103N/Y181C resistant mutant strain of HIV-1 with $\mathrm{EC}_{50}$ values in low-micromolar concentration ranges. Compounds $6 \mathbf{b 1}\left(\mathrm{EC}_{50}=0.55 \mu \mathrm{M}\right.$ with a 76.4 -fold resistance ratio) and $6 \mathbf{b 4}\left(\mathrm{EC}_{50}=0.51 \mu \mathrm{M}\right.$ with a 72.7 -fold resistance ratio $)$ were more active than reference drugs NVP, DLV and EFV, however, they were less potent than AZT and ETV $\left(\mathrm{EC}_{50}=0.034 \mu \mathrm{M}\right.$ with a 15.5 -fold resistance ratio). It is interesting to note that, compounds with $4-\mathrm{SO}_{2} \mathrm{NH}_{2}-\mathrm{Ph}$ group $(\mathbf{6 a 4}, \mathbf{6 b} 4$ and $\mathbf{6 c 4})$ showed better potency against resistant mutant strain of HIV-1 among each series $\left(-\mathrm{NH}_{2}\right.$ series, -NHMe series and -OMe series), which could also be observed in NNRTIs of other structural type, such as benzophenone $(\text { GW678248) })^{28}$ and triazolylthioacetanilide (VRX-480773) ${ }^{29}$ NNRTIs. However, compounds with 4-COOEt-Ph group (6a2, 6b2 and 6c2) displayed no activity against resistant mutant strain of HIV-1.

\subsection{Molecular simulation analysis}

In view of piperidine-substituted triazine derivatives and piperidine-linked aminopyrimidine derivatives targeting at the site of RT, ${ }^{15-17}$ we decided to investigate the binding mode of the newly synthesized NNRTIs. Potent compounds $\mathbf{6 a 1}$ and $\mathbf{6 b 3}$ were docked into non-nucleoside inhibitor binding pocket (NNIBP) of wild-type HIV-1 RT (PDB code: 3M8Q) using the software Surflex-Dock SYBYL-X 1.1 and the docking results were showed by PyMOL 0.99. Default parameters were used as described in the SYBYL-X 1.1 manual unless otherwise specified.

As shown in Figure 3, the new compounds $6 \mathbf{a} 1$ and $\mathbf{6 b} 3$ could bind into the NNIBP similar with piperidine-linked aminopyrimidine derivatives. ${ }^{15}$ Detailed analysis of the docking results revealed the following notable features that may clarify the mechanism of action of piperidine-substituted triazine derivatives. (1) Mesityl moiety of compounds 6a1 and $\mathbf{6 b 3}$ fits into the important hydrophobic sub-pocket, which is formed by aromatic amino acid residues Y181, Y188, F227 and W229, exhibiting $\pi-\pi$ interaction with these residues. (2) The new compounds form two hydrogen bonds with backbone carbonyl and backbone $\alpha$-amino of residue K101, similar to that observed in DAPY compounds. Additionally, the $-\mathrm{NH}_{2}$ and -NHMe groups can form a hydrogen bond with amino acid E138 that may improve stability of RT-inhibitor complex and the affinity between RT and inhibitor. (3) The substituted piperidine sits between amino acid Y318 and V106, and the polar hydrophilic substituents (compound 6a1) and heterocycle (compound 6b3) is located toward a solvent exposure region, contacting either side chain of amino acid L234 or P236 (Fig. 3c). This binding model supports our initial design hypothesis that introduction of $-\mathrm{NH}_{2}$ group at the triazine ring may improve hydrogen bond interaction with amino acid residues of the binding pocket, and polar hydrophilic substituents and heterocycle point directly into the protein/solvent interface. 
Table 1

Activity and cytotoxicity against HIV-1 (wild-type, IIIB) and HIV-2 (ROD) strains in MT-4 cells

\begin{tabular}{|c|c|c|c|c|c|c|}
\hline \multirow[t]{2}{*}{ Compds } & \multirow[t]{2}{*}{$\mathrm{R}$} & \multirow[t]{2}{*}{$\mathrm{Ar}$} & \multicolumn{2}{|c|}{$\mathrm{EC}_{50}{ }^{\mathrm{a}}$} & \multirow[t]{2}{*}{$\mathrm{CC}_{50}{ }^{\mathrm{b}}(\mu \mathrm{M})$} & \multirow[t]{2}{*}{$\mathrm{SI}^{\mathrm{c}}$} \\
\hline & & & HIV-1 III $(\mathrm{nM})$ & HIV-2 ROD $(\mu \mathrm{M})$ & & \\
\hline $6 a 1$ & $\mathrm{NH}_{2}$ & Pyridin-4-yl & $4.90 \pm 2.40$ & $>20.12$ & $20.12 \pm 8.10$ & 4108 \\
\hline $6 a 2$ & $\mathrm{NH}_{2}$ & 4-COOEt-Ph & $11.55 \pm 0.51$ & $>5.91$ & $5.91 \pm 1.37$ & 512 \\
\hline $6 a 3$ & $\mathrm{NH}_{2}$ & $4-\mathrm{CONH}_{2}-\mathrm{Ph}$ & $20.43 \pm 19.73$ & $>74.36$ & $74.36 \pm 18.94$ & 3640 \\
\hline $6 a 4$ & $\mathrm{NH}_{2}$ & $4-\mathrm{SO}_{2} \mathrm{NH}_{2}-\mathrm{Ph}$ & $5.75 \pm 2.64$ & $>19.85$ & $19.85 \pm 4.52$ & 3451 \\
\hline $6 \mathbf{5} 5$ & $\mathrm{NH}_{2}$ & $4-\mathrm{SO}_{2} \mathrm{Me}-\mathrm{Ph}$ & $5.55 \pm 1.48$ & $>5.06$ & $5.06 \pm 2.49$ & 911 \\
\hline $6 a 6$ & $\mathrm{NH}_{2}$ & Phenyl & $10.25 \pm 0.98$ & $>23.59$ & $23.59 \pm 3.40$ & 2302 \\
\hline $6 a 7$ & $\mathrm{NH}_{2}$ & $4-\mathrm{NO}_{2}-\mathrm{Ph}$ & $7.87 \pm 1.41$ & $>3.46$ & $3.46 \pm 1.58$ & 439 \\
\hline $6 a 8$ & $\mathrm{NH}_{2}$ & $4-\mathrm{CN}-\mathrm{Ph}$ & $5.66 \pm 3.13$ & $>3.26$ & $3.26 \pm 1.18$ & 576 \\
\hline 6b1 & NHMe & Pyridin-4-yl & $7.25 \pm 1.19$ & $>25.80$ & $25.80 \pm 1.15$ & 3558 \\
\hline $6 b 2$ & NHMe & 4-COOEt-Ph & 16. $66 \pm 7.94$ & $>4.95$ & $4.95 \pm 0.17$ & 297 \\
\hline $6 b 3$ & NHMe & $4-\mathrm{CONH}_{2}-\mathrm{Ph}$ & $4.61 \pm 1.90$ & $>27.39$ & $27.39 \pm 2.34$ & 5945 \\
\hline $6 b 4$ & NHMe & $4-\mathrm{SO}_{2} \mathrm{NH}_{2}-\mathrm{Ph}$ & $6.99 \pm 1.09$ & $>14.83$ & $14.83 \pm 2.49$ & 2122 \\
\hline $6 \mathbf{b 5}$ & NHMe & $4-\mathrm{SO}_{2} \mathrm{Me}-\mathrm{Ph}$ & $6.06 \pm 2.04$ & $>9.64$ & $9.64 \pm 3.12$ & 1590 \\
\hline $6 c 1$ & OMe & Pyridin-4-yl & $13.32 \pm 2.88$ & $>30.91$ & $30.91 \pm 2.23$ & 2320 \\
\hline $6 c 2$ & OMe & 4-COOEt-Ph & $14.71 \pm 7.04$ & $>8.48$ & $8.48 \pm 2.03$ & 577 \\
\hline $6 c 3$ & OMe & $4-\mathrm{CONH}_{2}-\mathrm{Ph}$ & $8.64 \pm 1.49$ & $>33.43$ & $33.43 \pm 8.98$ & 3869 \\
\hline $6 c 4$ & OMe & $4-\mathrm{SO}_{2} \mathrm{NH}_{2}-\mathrm{Ph}$ & $10.62 \pm 2.58$ & $>19.63$ & $19.63 \pm 2.67$ & 1849 \\
\hline $6 c 5$ & OMe & $4-\mathrm{SO}_{2} \mathrm{Me}-\mathrm{Ph}$ & $11.90 \pm 4.54$ & $>13.45$ & $13.45 \pm 3.48$ & 1130 \\
\hline NVP & & & $200.40 \pm 105.31$ & & $>15.02$ & $>75$ \\
\hline DLV & & & $35.01 \pm 4.73$ & & $>36.19$ & $>1034$ \\
\hline EFV & & & $6.57 \pm 0.87$ & & $>6.34$ & $>964$ \\
\hline AZT & & & $6.00 \pm 0.57$ & $0.007 \pm 0.0008$ & $\geqslant 49.77$ & $\geqslant 8295$ \\
\hline DDC & & & $1394.28 \pm 50.22$ & $1.67 \pm 0.25$ & $>94.69$ & $>68$ \\
\hline ETV $^{\text {d26 }}$ & & & $2.2 \pm 0.4$ & $>27.78$ & $27.78 \pm 11.53$ & 12884 \\
\hline
\end{tabular}

${ }^{\mathrm{a}} \mathrm{EC}_{50}$ : Concentration of compound required to achieve 50\% protection of MT-4 cell against HIV-1-induced cytotoxicity, as determined by the MTT method.

b $\mathrm{CC}_{50}$ : Concentration required to reduce the viability of mock-infected cells by $50 \%$, as determined by the MTT method.

c SI: Selectivity index, the ratio of $\mathrm{CC}_{50} / \mathrm{EC}_{50}^{\mathrm{HIV}-1 \mathrm{IIIB}}$.

d ETV: Etravirine. The data were obtained from the same laboratory (Rega Institute for Medical Research, K.U. Leuven, Belgium).

Overall, all these analyses were in accordance with the biological data. Apparently, the new compounds showed excellent activity against wild-type HIV-1 as they can bind into the NNIBP of wild-type HIV-1 RT and exhibit interactions with NNIBP. However, the new compounds displayed less potent activity against K103N/ Y181C resistant mutant strain of HIV-1 because of the following reasons according to the docking studies. First, the new compounds form hydrogen bonds with amino acid K101 backbone, whereas piperidine-linked aminopyrimidine derivatives form another hydrogen bond with K103 backbone through a water bridge, ${ }^{15}$ and this hydrogen bond interaction with main chain is unlikely to be disrupted by side chain mutations. Second, mesityl moiety which fits into the hydrophobic sub-pocket keeps parallel to the side chain phenyl of amino acid Y181 and forms strong $\pi$ $\pi$ interaction, when resistant mutation at Y181 side chain emerged the dependent $\pi-\pi$ interaction lost. Further structural optimization will consider these aspects analyzed above.

\section{Conclusion}

In the present paper, a novel series of piperidine substituted triazine derivatives were designed, synthesized and evaluated in
MT-4 cells along with preliminary SAR analysis. Screening results indicated that most compounds showed excellent activity against wild-type $\mathrm{HIV}-1$ with $\mathrm{EC}_{50}$ values in low nanomolar concentration range $\left(6 \mathbf{b 3}, \mathrm{EC}_{50}=4.61 \mathrm{nM}, \mathrm{SI}=5945\right)$ and high activity against K103N/Y181C resistant mutant strain of HIV-1 with $\mathrm{EC}_{50}$ values in low micromolar concentration range $\left(\mathbf{6 b 1}, \mathrm{EC}_{50}=0.55 \mu \mathrm{M}\right.$ with a 76.4-fold resistance ratio; $6 \mathbf{b} 4 \mathrm{EC}_{50}=0.51 \mu \mathrm{M}$ with a 72.7-fold resistance ratio). In addition, we also built the molecular modes to analyze the interactions between the analogs and wild-type HIV-1 RT. Further studies are ongoing in our laboratories and will be reported in due course.

\section{Experimental section}

\subsection{Chemistry}

All melting points were determined on a micromelting point apparatus and are uncorrected. Infrared spectra (IR) were recorded with a Nexus 470 FT-IR Spectrometer. ${ }^{1} \mathrm{H}$ NMR spectra were obtained on a Brucker Avance-600 NMR-spectrometer in the indicated solvents. Chemical shifts are expressed in $\delta$ units and TMS as internal reference. Mass spectra were taken on a LC Autosampler 
Table 2

Activity against K103N+Y181C mutant strain of HIV-1 (RES056) in MT-4 cells

\begin{tabular}{lllll}
\hline Compds & $\mathrm{EC}_{50}(\mu \mathrm{M})$ & Fold-res. $^{\mathrm{a}}$ & $\mathrm{CC}_{50}(\mu \mathrm{M})$ & $\mathrm{SI}$ \\
\hline $\mathbf{6 a 1}$ & $0.97 \pm 0.07$ & 198.8 & $20.12 \pm 8.10$ & 21 \\
$\mathbf{6 a 2}$ & $>5.91$ & $>511.6$ & $5.91 \pm 1.37$ & $<1$ \\
$\mathbf{6 a 3}$ & $3.33 \pm 3.19$ & 162.8 & $74.36 \pm 18.94$ & 22 \\
$\mathbf{6 a 4}$ & $0.61 \pm 0.01$ & 105.7 & $19.85 \pm 4.52$ & 32 \\
$\mathbf{6 a 5}$ & $4.92 \pm 4.79$ & 887.5 & $5.06 \pm 2.49$ & 1 \\
$\mathbf{6 a 6}$ & $4.93 \pm 0.03$ & 481.3 & $23.59 \pm 3.40$ & 5 \\
$\mathbf{6 a 7}$ & $>3.46$ & $>439.1$ & $3.46 \pm 1.58$ & $<1$ \\
$\mathbf{6 a 8}$ & $>3.26$ & $>575.8$ & $3.26 \pm 1.18$ & $<1$ \\
$\mathbf{6 b 1}$ & $0.55 \pm 0.22$ & 76.4 & $25.80 \pm 1.15$ & 47 \\
$\mathbf{6 b 2}$ & $>4.95$ & $>297.0$ & $4.95 \pm 0.17$ & $<1$ \\
$\mathbf{6 b 3}$ & $0.56 \pm 0.12$ & 121.6 & $27.39 \pm 2.34$ & 49 \\
$\mathbf{6 b 4}$ & $0.51 \pm 0.27$ & 72.7 & $14.83 \pm 2.49$ & 29 \\
$\mathbf{6 b 5}$ & $3.33 \pm 3.33$ & 549.8 & $9.64 \pm 3.12$ & 3 \\
$\mathbf{6 c 1}$ & $1.48 \pm 0.31$ & 111.1 & $30.91 \pm 2.23$ & 21 \\
$\mathbf{6 c 2}$ & $>8.48$ & $>576.6$ & $8.48 \pm 2.03$ & $<1$ \\
$\mathbf{6 c 3}$ & $1.11 \pm 0.17$ & 128.3 & $33.43 \pm 8.98$ & 30 \\
$\mathbf{6 c 4}$ & $0.94 \pm 0.04$ & 88.2 & $19.63 \pm 2.67$ & 21 \\
$\mathbf{6 c 5}$ & $\geqslant 1.59$ & $\geqslant 133.3$ & $13.45 \pm 3.48$ & $\leqslant 8$ \\
NVP & $>15.02$ & $>75.0$ & $>15.02$ & $\mathrm{X} 1^{\mathrm{b}}$ \\
$\mathrm{DLV}$ & $>36.19$ & $>1033.6$ & $>36.19$ & $\mathrm{X} 1$ \\
EFV & $0.55 \pm 0.06$ & 83.6 & $>6.34$ & $>12$ \\
AZT & $0.01 \pm 0.009$ & 1.9 & $\geqslant 49.77$ & $\geqslant 4397$ \\
DDC & & 15.5 & $>94.69$ & 817 \\
ETV 26 & $0.034 \pm 0.0046$ & $27.78 \pm 11.53$ & \\
\hline a & & & & \\
\hline
\end{tabular}

a Fold-res: Fold resistance, the ratio of $\mathrm{EC}_{50}$ value against drug-resistant strain and $\mathrm{EC}_{50}$ of the wild-type HIV-1 IIIB ( $\mathrm{EC}_{50}^{\text {mutant strains }} / \mathrm{EC}_{50}^{\mathrm{wt}}$.

b $\mathrm{X} 1$ : stands for $\geqslant 1$ or $<1$.

ETV: Etravirine. The data were obtained from the same laboratory (Rega Institute for Medical Research, K.U. Leuven, Belgium).

Device: Standard G1313A instrument. TLC was performed on Silica Gel GF254 for TLC (Merck) and spots were visualized by iodine vapors or by irradiation with UV light $(254 \mathrm{~nm})$. Flash column chromatography was performed on column packed with Silica Gel 60 (200-300 mesh). Solvents were reagent grade and, when necessary, were purified and dried by standard methods. Concentration of the reaction solutions involved the use of rotary evaporator at reduced pressure.

\subsubsection{General procedure for the synthesis of 4,6-dichloro- $N$ - mesityl-1,3,5-triazin-2-amine (2)}

To a solution of cyanuric chloride $(\mathbf{1}, 0.37 \mathrm{~g}, 2 \mathrm{mmol})$ in THF $(15 \mathrm{~mL})$ at $0{ }^{\circ} \mathrm{C}$ was slowly added $\mathrm{K}_{2} \mathrm{CO}_{3}(0.55 \mathrm{~g}, 4 \mathrm{mmol})$ and 2,4,6-trimethylaniline $(0.28 \mathrm{~g}, 2 \mathrm{mmol})$. The resulting mixture was stirred at $0{ }^{\circ} \mathrm{C}$ for $3 \mathrm{~h}$ (monitored by TLC). The solvent was removed under reduced pressure and water $(20 \mathrm{~mL})$ was added and extracted with $\mathrm{CH}_{2} \mathrm{Cl}_{2}(2 \times 10 \mathrm{~mL})$. Combined organic phase was washed with brine, dried over anhydrous $\mathrm{Na}_{2} \mathrm{SO}_{4}$, filtered and concentrated. Purification on silica gel gave $\mathbf{2}$ as an off-white solid. Yield: $91 \%$, mp: $197-199{ }^{\circ} \mathrm{C} .{ }^{1} \mathrm{H}$ NMR (DMSO- $\left.d_{6}, \mathrm{ppm}\right) \delta: 10.45$ (s, $1 \mathrm{H}, \mathrm{NH}), 6.94(\mathrm{~s}, 2 \mathrm{H}, \mathrm{PhH}), 2.25\left(\mathrm{~s}, 3 \mathrm{H}, \mathrm{CH}_{3}\right), 2.08(\mathrm{~s}, 6 \mathrm{H}$, $\left.2 \times \mathrm{CH}_{3}\right)$. ESI-MS: $m / z 283.3(\mathrm{M}+1), 285.3(\mathrm{M}+3), 287.3(\mathrm{M}+5)$. $\mathrm{C}_{12} \mathrm{H}_{12} \mathrm{Cl}_{2} \mathrm{~N}_{4}$ [282.04].

\subsubsection{General procedure for the synthesis of 6-chloro- $N^{2}$ -} mesityl- $N^{4}$-(1-Boc-piperidin-4-yl)-1,3,5-triazine-2,4-diamine (3)

A solution of crude intermediate $2(0.56 \mathrm{~g}, 2 \mathrm{mmol})$ in THF/acetone $/ \mathrm{H}_{2} \mathrm{O}(4: 1: 1,30 \mathrm{~mL})$ was treated with 4-amino-1-Boc-piperidine $(0.4 \mathrm{~g}, 2 \mathrm{mmol})$ and $5 \% \mathrm{w} / \mathrm{v}$ aqueous $\mathrm{NaHCO}_{3}(8 \mathrm{~mL})$. The mixture was stirred at $30^{\circ} \mathrm{C}$ for $8 \mathrm{~h}$, after that, THF/acetone was evaporated under reduced pressure and extracted with ethyl acetate $(2 \times 10 \mathrm{~mL})$. Combined extracts were washed with saturated sodium chloride $(10 \mathrm{~mL})$, dried over anhydrous $\mathrm{Na}_{2} \mathrm{SO}_{4}$, and evaporated in vacuo to give the crude product. Purification on silica gel gave 3 as an off-white solid. Yield: $92 \%$, mp: $203-205{ }^{\circ} \mathrm{C} .{ }^{1} \mathrm{H}$ NMR
(DMSO-d $\left.d_{6}, \mathrm{ppm}\right) \delta: 9.13(\mathrm{~m}, 1 \mathrm{H}), 7.77(\mathrm{~m}, 1 \mathrm{H}), 6.87(\mathrm{~s}, 2 \mathrm{H}, \mathrm{PhH})$ $3.91(\mathrm{~m}, 3 \mathrm{H}), 2.81(\mathrm{~s}, 2 \mathrm{H}), 2.22\left(\mathrm{~d}, 3 \mathrm{H}, \mathrm{CH}_{3}\right), 2.07\left(\mathrm{~d}, 6 \mathrm{H}, 2 \times \mathrm{CH}_{3}\right)$, 1.37 (s, 9H). ESI-MS: m/z $447.5(\mathrm{M}+1), 448.5(\mathrm{M}+2), 449.5(\mathrm{M}+3)$. $\mathrm{C}_{22} \mathrm{H}_{31} \mathrm{ClN}_{6} \mathrm{O}_{2}$ [446.22].

4.1.3. General procedure for the synthesis of $N^{2}$-mesityl- $N^{4}-(1-$ Boc-piperidin-4-yl)-1,3,5-triazine-2,4,6-triamine (4a), $N^{2}$ mesityl- $N^{4}$-methyl- $N^{6}$-(1-Boc-piperidin-4-yl)-1,3,5-triazine2,4,6-triamine (4b) and $N^{2}$-mesityl-6-methoxy- $N^{4}$-(1-Bocpiperidin-4-yl)-1,3,5-triazine-2,4-diamine (4c)

To a solution of solid $3(7.1 \mathrm{~g}, 16 \mathrm{mmol})$ in THF $(20 \mathrm{~mL})$ was added ammonia ( $28 \% \mathrm{w} / \mathrm{v}, 100 \mathrm{~mL})$. Then, the mixture was transferred to the reactor, sealed and placed at $100{ }^{\circ} \mathrm{C}$ for $5 \mathrm{~h}$ with a mechanical stirrer. The reaction solution was left to cool overnight and extracted with ethyl acetate $(3 \times 30 \mathrm{~mL})$. Combined extracts were washed with $2 \mathrm{~N} \mathrm{HCl}$ and brine, dried over anhydrous $\mathrm{Na}_{2} \mathrm{SO}_{4}$, filtered and concentrated to give the crude product. Purification on silica gel gave $\mathbf{4 a}$ as an off-white solid. Yield: $82 \%$, mp: $144-146{ }^{\circ} \mathrm{C}$. ESI-MS: $m / z \quad 428.3(\mathrm{M}+1), 429.3 \quad(\mathrm{M}+2)$ $\mathrm{C}_{22} \mathrm{H}_{33} \mathrm{~N}_{7} \mathrm{O}_{2}$ [427.27].

Intermediate $3(0.22 \mathrm{~g}, 0.5 \mathrm{mmol})$ was dissolved in THF, followed by addition of saturated $\mathrm{NaHCO}_{3}(2 \mathrm{~mL})$ and $40 \% \mathrm{w} / \mathrm{v}$ aqueous methylamine $(0.2 \mathrm{~mL})$. The reaction mixture was stirred at $50{ }^{\circ} \mathrm{C}$ for $5 \mathrm{~h}$. THF was removed under reduced pressure and extracted with ethyl acetate $(2 \times 10 \mathrm{~mL})$. Combined organic phase was dried over anhydrous $\mathrm{Na}_{2} \mathrm{SO}_{4}$, filtered and concentrated under reduced pressure to give the product $\mathbf{4 b}$ as white solid. Yield: $96 \%$, mp: $131-133^{\circ} \mathrm{C}$, ESI-MS: $m / z \quad 442.5(\mathrm{M}+1), 443.5(\mathrm{M}+2)$ $\mathrm{C}_{23} \mathrm{H}_{35} \mathrm{~N}_{7} \mathrm{O}_{2}$ [441.29].

$\mathrm{Na}(0.35 \mathrm{~g}, 15 \mathrm{mmol})$ was dissolved in absolute $\mathrm{MeOH}(50 \mathrm{~mL})$ followed by addition of 6 -chloro- $N^{2}$-mesityl- $N^{4}$-(1-Boc-piperidin4-yl)-1,3,5-triazine-2,4-diamine (3) ( $4.5 \mathrm{~g}, 10 \mathrm{mmol}$ ). The reaction mixture was stirred at $60{ }^{\circ} \mathrm{C}$ for $4 \mathrm{~h}$. After removal of the solvent under reduced pressure, water $(20 \mathrm{~mL})$ was added and extracted with ethyl acetate $(2 \times 20 \mathrm{~mL})$. Combined organic phase was dried over anhydrous $\mathrm{Na}_{2} \mathrm{SO}_{4}$, filtered and concentrated under reduced pressure to give the product (4c) as white solid. Yield: $94 \%, \mathrm{mp}$ : 190-192 ${ }^{\circ} \mathrm{C}$, ESI-MS: $m / z 443.6(\mathrm{M}+1), 444.6(\mathrm{M}+2) . \mathrm{C}_{23} \mathrm{H}_{34} \mathrm{~N}_{6} \mathrm{O}_{3}$ [442.27].

4.1.4. General procedure for the synthesis of $N^{2}$-mesityl- $N^{4}$ (piperidin-4-yl)-1,3,5-triazine-2,4,6-triamine (5a), $N^{2}$-mesityl$N^{4}$-methyl- $N^{6}$-(piperidin-4-yl)-1,3,5-triazine-2,4,6-triamine (5b) and $N^{2}$-mesityl-6-methoxy- $N^{4}$-(piperidin-4-yl)-1,3,5-triazine2,4-diamine (5c)

TFA ( $4 \mathrm{~mL}, 54 \mathrm{mmol}$ ) was added dropwise under stirring to a solution of intermediate $4 \mathbf{a}(3.3 \mathrm{~g}, 7.7 \mathrm{mmol})$ in $\mathrm{CH}_{2} \mathrm{Cl}_{2}(20 \mathrm{~mL})$ at room temperature and stirred for $5 \mathrm{~h}$. To the reaction mixture was added water and neutralized with $2 \mathrm{~N} \mathrm{NaOH}$ to pH8, and the organic layer was separated and dried over anhydrous $\mathrm{Na}_{2} \mathrm{SO}_{4}$, filtered and concentrated under reduced pressure to give the product (5a) as white solid. Yield: $91 \%$, mp: $236-238^{\circ} \mathrm{C}$, ESI-MS: $\mathrm{m} / \mathrm{z} 328.2$ $(\mathrm{M}+1), 164.7((\mathrm{M}+2) / 2) . \mathrm{C}_{17} \mathrm{H}_{25} \mathrm{~N}_{7}$ [327.22].

Using intermediate $4 \mathbf{b}(0.3 \mathrm{~g}, 0.67 \mathrm{mmol})$ and TFA $(1 \mathrm{~mL}$, $13.5 \mathrm{mmol}$ ) and following the procedure as in the preparation of 5a to give 5b as a white solid. Yield: $95 \%$, mp: $139-141{ }^{\circ} \mathrm{C}$, ESIMS: $m / z 342.4(\mathrm{M}+1), 171.8((\mathrm{M}+2) / 2) . \mathrm{C}_{18} \mathrm{H}_{27} \mathrm{~N}_{7}$ [341.45].

Using intermediate $4 \mathrm{c}(0.2 \mathrm{~g}, 0.45 \mathrm{mmol})$ and TFA $(0.5 \mathrm{~mL}$, $6.7 \mathrm{mmol}$ ) and following the procedure as in the preparation of 5a to give 5c as a white solid. Yield: 95\%, mp: $225-227{ }^{\circ} \mathrm{C}$, ESIMS: $m / z 343.5(\mathrm{M}+1), 172.4((\mathrm{M}+2) / 2) . \mathrm{C}_{18} \mathrm{H}_{26} \mathrm{~N}_{6} \mathrm{O}$ [342.44].

\subsubsection{General procedure for the synthesis of target compounds} (6a1-6a8, 6b1-6b5 and 6c1-6c5)

Compounds $\mathbf{5 a}(\mathbf{5 b}$ or $\mathbf{5 c}$ ) was dissolved in anhydrous DMF $\left(10 \mathrm{~mL}\right.$ ) in the presence of anhydrous $\mathrm{K}_{2} \mathrm{CO}_{3}$ (2 equiv) at $0{ }^{\circ} \mathrm{C}$, fol- 

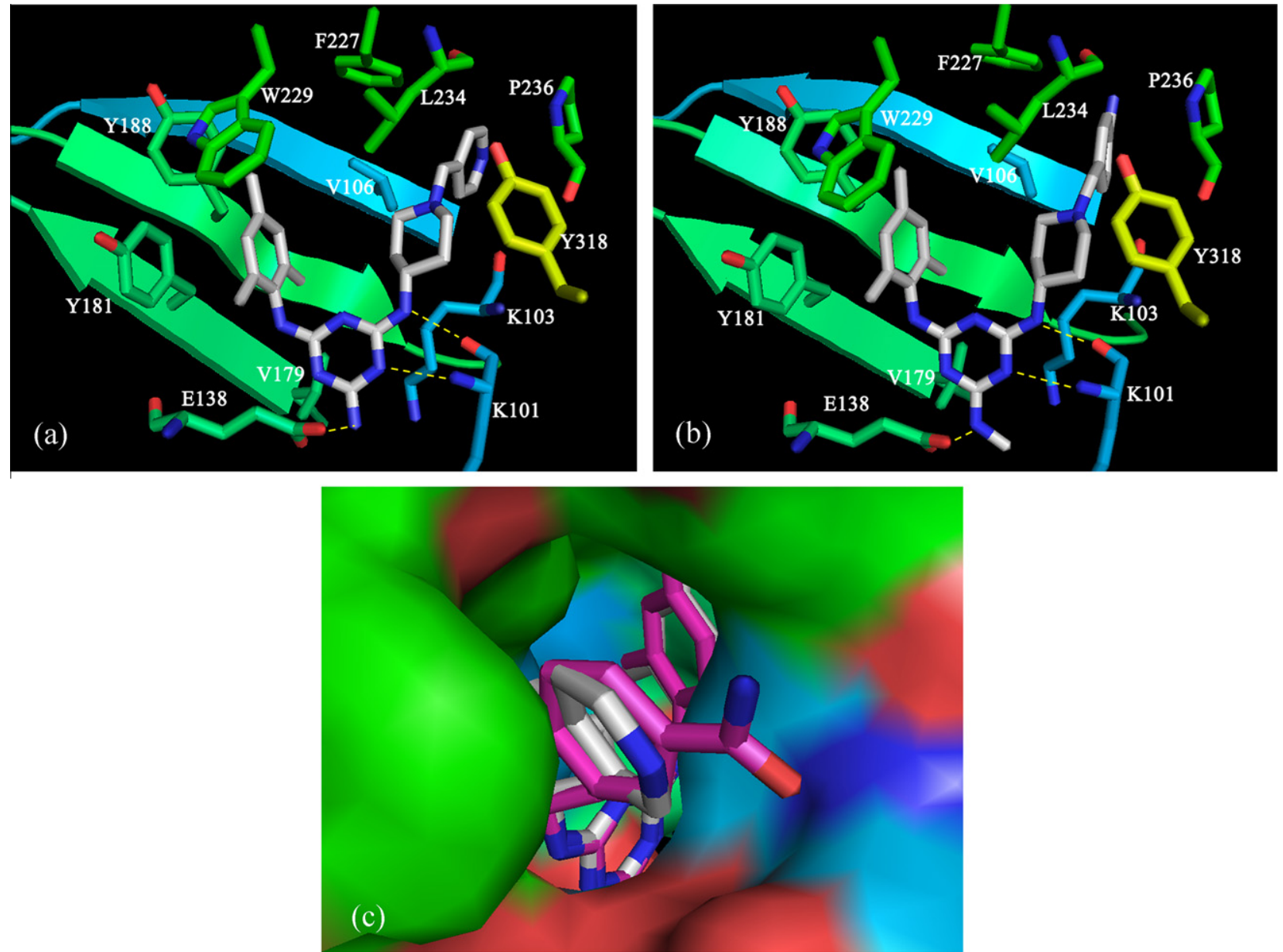

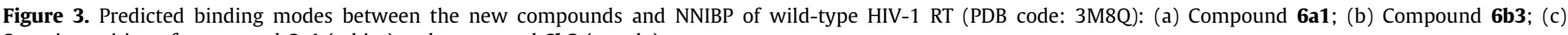
Superimposition of compound $\mathbf{6 a 1}$ (white) and compound $\mathbf{6 b} 3$ (purple).

lowed by addition of appropriate substituted benzyl chloride (or 4picolyl chloride hydrochloride) (1.1 equiv). The reaction mixture was stirred at room temperature overnight. The solvent was removed under reduced pressure, and water $(20 \mathrm{~mL})$ was added. Extracted with ethyl acetate $(2 \times 10 \mathrm{~mL})$, and the organic phase was washed with saturated sodium chloride $(10 \mathrm{~mL})$, and dried over anhydrous $\mathrm{Na}_{2} \mathrm{SO}_{4}$ to give the corresponding crude products, which were purified by flash column chromatography to afford the target compounds 6a1-6a8 (6b1-6b5 or 6c1-6c5), respectively.

4.1.5.1. $\quad N^{2}$-mesityl- $N^{4}$-(1-(pyridin-4-ylmethyl)piperidin-4-yl)1,3,5-triazine-2,4,6-triamine (6a1). Pale yellow powder, yield: $67.6 \%$. Decomposed at $233{ }^{\circ} \mathrm{C} .{ }^{1} \mathrm{H}$ NMR $\left(\mathrm{CDCl}_{3}, \mathrm{ppm}\right) \delta$ : 8.59 (s, 2H, PhH), 6.97 (s, 2H, PhH), $4.85(\mathrm{~m}, 4 \mathrm{H}), 3.95(\mathrm{~m}, 1 \mathrm{H})$, $3.52\left(\mathrm{~s}, 2 \mathrm{H}, \mathrm{CH}_{2}\right), 2.81(\mathrm{~s}, 2 \mathrm{H}), 2.35\left(\mathrm{~s}, 3 \mathrm{H}, \mathrm{CH}_{3}\right), 2.25(\mathrm{~s}, 6 \mathrm{H}$, $\left.2 \times \mathrm{CH}_{3}\right), 2.05(\mathrm{~s}, 4 \mathrm{H}), 1.51(\mathrm{~s}, 2 \mathrm{H}) .{ }^{13} \mathrm{C} \mathrm{NMR}\left(100 \mathrm{MHz}, \mathrm{CDCl}_{3}\right.$, ppm) $\delta: 18.59,20.97,32.33,46.91,52.37,61.83,123.75,128.79$, 132.46, 136.59, 147.92, 149.80, 165.72, 167.23. IR $\left(\mathrm{KBr}, \mathrm{cm}^{-1}\right)$ : $3460\left(v_{\mathrm{NH}}^{\mathrm{as}}\right), 3399\left(v_{\mathrm{NH}}\right), 2936\left(v_{\mathrm{CH} 3}^{\mathrm{as}}\right), 1559,1487\left(v_{\mathrm{C}=\mathrm{N}}\right), 812\left(\omega_{\mathrm{C}=\mathrm{N}}\right)$. ESI-MS: $m / z 419.4(\mathrm{M}+1), 210.3((\mathrm{M}+2) / 2) . \mathrm{C}_{23} \mathrm{H}_{30} \mathrm{~N}_{8}$ [418.54].

4.1.5.2. ethyl 4-((4-(4-amino-6-(mesitylamino)-1,3,5-triazin-2ylamino)piperidin-1-yl)methyl)benzoate (6a2). White powder, yield: $69.4 \%$. Mp: $141-143{ }^{\circ} \mathrm{C} .{ }^{1} \mathrm{H}$ NMR $\left(\mathrm{CDCl}_{3}, \mathrm{ppm}\right) \delta$ : 7.99 (d, 2H, J = 7.8 Hz, PhH), 7.39 (s, 2H, PhH), 6.91 (s, 2H, PhH), $4.80(\mathrm{~m}, 3 \mathrm{H}), 4.37\left(\mathrm{q}, 2 \mathrm{H}, J=7.2 \mathrm{~Hz}, \mathrm{CH}_{2}\right), 3.80(\mathrm{~m}, 1 \mathrm{H}), 3.55(\mathrm{~s}$, $\left.2 \mathrm{H}, \mathrm{CH}_{2}\right), 2.77(\mathrm{~s}, 2 \mathrm{H}), 2.29\left(\mathrm{~s}, 3 \mathrm{H}, \mathrm{CH}_{3}\right), 2.19\left(\mathrm{~s}, 6 \mathrm{H}, 2 \times \mathrm{CH}_{3}\right)$, $1.94(\mathrm{~s}, 3 \mathrm{H}), 1.44(\mathrm{~m}, 2 \mathrm{H}), 1.39\left(\mathrm{t}, 3 \mathrm{H}, \mathrm{CH}_{3}\right) . \mathrm{IR}\left(\mathrm{KBr}, \mathrm{cm}^{-1}\right): 3386$ $\left(v_{\mathrm{NH}}^{\mathrm{as}}\right), 3316\left(v_{\mathrm{NH}}\right), 2939\left(v_{\mathrm{CH} 3}^{\mathrm{as}}\right), 1718\left(v_{\mathrm{C}=\mathrm{O}}\right), 1560,1494\left(v_{\mathrm{C}=\mathrm{N}}\right)$, $1276\left(v_{\mathrm{C}-\mathrm{O}-\mathrm{C}}^{\mathrm{as}}\right), 1106\left(v_{\mathrm{C}-\mathrm{O}-\mathrm{C}}^{\mathrm{s}}\right), 813\left(\omega_{\mathrm{C}=\mathrm{N}}\right)$. ESI-MS: $\mathrm{m} / \mathrm{z} 490.9$ $(\mathrm{M}+1), 246.0((\mathrm{M}+2) / 2) . \mathrm{C}_{27} \mathrm{H}_{35} \mathrm{~N}_{7} \mathrm{O}_{2}$ [489.61].

4.1.5.3. 4-((4-(4-amino-6-(mesitylamino)-1,3,5-triazin-2-ylamino)piperidin-1-yl)methyl)benzamide (6a3). White powder, yield: $71.2 \%$. Decomposed at $266{ }^{\circ} \mathrm{C} .{ }^{1} \mathrm{H}$ NMR (DMSO- $\left.d_{6}, \mathrm{ppm}\right) \delta$ : $7.82(\mathrm{~s}, 2 \mathrm{H}, \mathrm{PhH}), 7.35$ (s, 2H, PhH), $6.82(\mathrm{~s}, 2 \mathrm{H}, \mathrm{PhH}), 3.48(\mathrm{~d}, 2 \mathrm{H}$, $J=24 \mathrm{~Hz}), 2.76(\mathrm{~s}, 2 \mathrm{H}), 2.20\left(\mathrm{~s}, 3 \mathrm{H}, \mathrm{CH}_{3}\right), 2.08\left(\mathrm{~s}, 6 \mathrm{H}, 2 \times \mathrm{CH}_{3}\right)$, $1.88-1.99(\mathrm{~m}, 2 \mathrm{H}), 1.66-1.76(\mathrm{~m}, 2 \mathrm{H}), 1.39-1.49(\mathrm{~m}, 2 \mathrm{H}) .{ }^{13} \mathrm{C}$ NMR $\left(100 \mathrm{MHz}, \mathrm{DMSO}-d_{6}, \mathrm{ppm}\right) \delta$ : 18.79, 20.94, 32.31, 46.81, $52.72,65.49,127.88,128.56,129.01,133.50,134.50,135.09$, $136.38,142.23,165.95,167.48,168.27 . \mathrm{IR}\left(\mathrm{KBr}, \mathrm{cm}^{-1}\right): 3397$ $\left(v_{\mathrm{NH}}^{\mathrm{as}}\right), 2924\left(v_{\mathrm{CH} 3}^{\mathrm{as}}\right), 1671\left(v_{\mathrm{C}=\mathrm{O}}\right), 1612\left(\beta_{\mathrm{NH}}\right), 1568,1494\left(v_{\mathrm{C}=\mathrm{N}}\right)$, $813\left(\omega_{\mathrm{C}=\mathrm{N}}\right)$. ESI-MS: $m / z 461.6(\mathrm{M}+1) . \mathrm{C}_{25} \mathrm{H}_{32} \mathrm{~N}_{8} \mathrm{O}$ [460.57].

4.1.5.4. 4-((4-(4-amino-6-(mesitylamino)-1,3,5-triazin-2-ylamino)piperidin-1-yl)methyl)benzenesulfonamide

(6a4). White powder, yield: $70.4 \%$. Decomposed at $242{ }^{\circ} \mathrm{C} .{ }^{1} \mathrm{H}$ NMR (DMSO-d $\left.d_{6}, \mathrm{ppm}\right) \delta: 7.77(\mathrm{~s}, 2 \mathrm{H}, \mathrm{PhH}), 7.47(\mathrm{~d}, 2 \mathrm{H}, J=9.6 \mathrm{~Hz}$, $\mathrm{PhH}), 7.31(\mathrm{~s}, 2 \mathrm{H}), 6.82(\mathrm{~s}, 2 \mathrm{H}, \mathrm{PhH}), 6.11(\mathrm{~d}, 1 \mathrm{H}, J=3.0 \mathrm{~Hz}), 3.51$ (d, $2 \mathrm{H}, J=24.6 \mathrm{~Hz}), 2.76(\mathrm{~s}, 2 \mathrm{H}), 2.20\left(\mathrm{~s}, 3 \mathrm{H}, \mathrm{CH}_{3}\right), 2.08(\mathrm{~s}, 6 \mathrm{H}$, $\left.2 \times \mathrm{CH}_{3}\right), 1.83-2.05(\mathrm{~m}, 2 \mathrm{H}), 1.62-1.80(\mathrm{~m}, 2 \mathrm{H}), 1.45-1.55(\mathrm{~m}$, $2 \mathrm{H})$. IR $\left(\mathrm{KBr}, \mathrm{cm}^{-1}\right): 3457\left(v_{\mathrm{NH}}^{\mathrm{as}}\right), 3420\left(v_{\mathrm{NH}}\right), 2946\left(v_{\mathrm{CH} 3}^{\mathrm{as}}\right), 1556$, $1486\left(v_{\mathrm{C}=\mathrm{N}}\right), 1369\left(v_{\mathrm{O}}^{\mathrm{as}} \mathrm{S}_{=0}\right), 1164\left(v_{\mathrm{O}=\mathrm{S}=\mathrm{O}}\right), 1097\left(v_{\mathrm{S}=\mathrm{O}}\right), 813$ $\left(\omega_{\mathrm{C}=\mathrm{N}}\right)$. ESI-MS: $\mathrm{m} / \mathrm{z} 497.6(\mathrm{M}+1), 249.5((\mathrm{M}+2) / 2) \cdot \mathrm{C}_{24} \mathrm{H}_{32} \mathrm{~N}_{8} \mathrm{O}_{2} \mathrm{~S}$ [496.63]. 
4.1.5.5. $\quad N^{2}$-mesityl- $N^{4}$-(1-(4-(methylsulfonyl)benzyl)piperidin4-yl)-1,3,5-triazine-2,4,6-triamine (6a5). White powder, yield: $66.8 \%$. Decomposed at $242{ }^{\circ} \mathrm{C} .{ }^{1} \mathrm{H}$ NMR $\left(\mathrm{CDCl}_{3}, \mathrm{ppm}\right) \delta$ : 7.89 (d, 2H, J = 6.6 Hz, PhH), 7.53 (s, 2H, PhH), 6.91 (s, 2H, PhH), $4.83(\mathrm{~m}, 3 \mathrm{H}), 3.80(\mathrm{~m}, 1 \mathrm{H}), 3.57\left(\mathrm{~s}, 2 \mathrm{H}, \mathrm{CH}_{2}\right), 3.06\left(\mathrm{~s}, 3 \mathrm{H}, \mathrm{CH}_{3}\right)$, $2.75(\mathrm{~s}, 2 \mathrm{H}), 2.29\left(\mathrm{~s}, 3 \mathrm{H}, \mathrm{CH}_{3}\right), 2.19\left(\mathrm{~s}, 6 \mathrm{H}, 2 \times \mathrm{CH}_{3}\right), 1.94(\mathrm{~s}, 2 \mathrm{H})$, 1.43 (s, 2H). IR (KBr, cm $\left.{ }^{-1}\right): 3422\left(v_{\mathrm{NH}}\right), 2943\left(v_{\mathrm{CH} 3}^{\text {as }}\right), 1560,1513$ $\left(v_{\mathrm{C}=\mathrm{N}}\right), 1372\left(v_{\mathrm{as}}^{\mathrm{as}} \mathrm{S}\right), 1150\left(v_{\mathrm{O}=\mathrm{S}=\mathrm{O}}\right), 1090\left(v_{\mathrm{S}=\mathrm{O}}\right), 812\left(\omega_{\mathrm{C}=\mathrm{N}}\right)$. ESI-MS: $m / z$ 496.6 (M+1). $\mathrm{C}_{25} \mathrm{H}_{33} \mathrm{~N}_{7} \mathrm{O}_{2} \mathrm{~S}$ [495.64].

4.1.5.6. $\quad N^{2}$-(1-benzylpiperidin-4-yl)- $N^{4}$-mesityl-1,3,5-triazine2,4,6-triamine (6a6). White powder, yield: 68.5\%. Mp: 253$255{ }^{\circ} \mathrm{C} .{ }^{1} \mathrm{H}$ NMR $\left(\mathrm{CDCl}_{3}, \mathrm{ppm}\right) \delta: 7.31(\mathrm{~s}, 4 \mathrm{H}, \mathrm{PhH}), 6.90(\mathrm{~s}, 2 \mathrm{H}$, $\mathrm{PhH}), 4.75(\mathrm{~m}, 4 \mathrm{H}), 3.90(\mathrm{~m}, 1 \mathrm{H}), 3.52\left(\mathrm{~s}, 2 \mathrm{H}, \mathrm{CH}_{2}\right), 2.81(\mathrm{~s}, 2 \mathrm{H})$, $2.29\left(\mathrm{~s}, 3 \mathrm{H}, \mathrm{CH}_{3}\right), 2.19\left(\mathrm{~s}, 6 \mathrm{H}, 2 \times \mathrm{CH}_{3}\right), 1.96(\mathrm{~s}, 4 \mathrm{H}), 1.46(\mathrm{~s}, 2 \mathrm{H})$. IR $\left(\mathrm{KBr}, \mathrm{cm}^{-1}\right): 3463\left(v_{\mathrm{NH}}^{\mathrm{as}}\right), 3402\left(v_{\mathrm{NH}}\right), 3309\left(v_{\mathrm{NH}}\right), 2934\left(v_{\mathrm{CH} 3}^{\mathrm{as}}\right)$, 1557, $1486\left(v_{\mathrm{C}=\mathrm{N}}\right), 811\left(\omega_{\mathrm{C}=\mathrm{N}}\right)$. ESI-MS: $\mathrm{m} / z 418.4(\mathrm{M}+1), 209.9$ $((\mathrm{M}+2) / 2) . \mathrm{C}_{24} \mathrm{H}_{31} \mathrm{~N}_{7}$ [417.55].

4.1.5.7. $\quad N^{2}$-mesityl- $N^{4}-(1-(4-n i t r o b e n z y l) p i p e r i d i n-4-y l)-1,3,5-$ triazine-2,4,6-triamine (6a7). White powder, yield: $69.1 \%$. Mp: $248-250{ }^{\circ} \mathrm{C} .{ }^{1} \mathrm{H}$ NMR $\left(\mathrm{CDCl}_{3}, \mathrm{ppm}\right) \delta: 8.17$ (s, $\left.2 \mathrm{H}, \mathrm{PhH}\right), 7.50$ (s, 2H, PhH), $6.91(\mathrm{~s}, 2 \mathrm{H}, \mathrm{PhH}), 4.84(\mathrm{~m}, 4 \mathrm{H}), 3.80(\mathrm{~m}, 1 \mathrm{H}), 3.58(\mathrm{~s}$, $\left.2 \mathrm{H}, \mathrm{CH}_{2}\right), 2.74(\mathrm{~s}, 2 \mathrm{H}), 2.29\left(\mathrm{~s}, 3 \mathrm{H}, \mathrm{CH}_{3}\right), 2.19\left(\mathrm{~s}, 6 \mathrm{H}, 2 \times \mathrm{CH}_{3}\right)$, $1.94(\mathrm{~s}, 2 \mathrm{H}), 1.43(\mathrm{~s}, 2 \mathrm{H})$. IR $\left(\mathrm{KBr}, \mathrm{cm}^{-1}\right): 3456\left(v_{\mathrm{NH}}^{\mathrm{as}}\right), 3411\left(v_{\mathrm{NH}}\right)$, $3309\left(v_{\mathrm{NH}}\right), 2920\left(v_{\mathrm{CH} 3}^{\mathrm{as}}\right), 1557,1483\left(v_{\mathrm{C}=\mathrm{N}}\right), 1518\left(v_{\mathrm{NO} 2}^{\mathrm{as}}\right), 813\left(\omega_{\mathrm{C}=\mathrm{N}}\right)$. ESI-MS: $m / z$ 463.4 (M+1), $232.3((\mathrm{M}+2) / 2) . \mathrm{C}_{24} \mathrm{H}_{30} \mathrm{~N}_{8} \mathrm{O}_{2}$ [462.55].

4.1.5.8. 4-((4-(4-amino-6-(mesitylamino)-1,3,5-triazin-2-ylamino)piperidin-1-yl)methyl)benzonitrile (6a8). White powder, yield: $71.0 \%$. Decomposed at $228{ }^{\circ} \mathrm{C} .{ }^{1} \mathrm{H}$ NMR $\left(\mathrm{CDCl}_{3}, \mathrm{ppm}\right) \delta$ : 7.60 (d, 2H, J = 7.2 Hz, PhH), 7.44 (s, 2H, PhH), 6.91 (s, 2H, PhH), $4.84(\mathrm{~m}, 3 \mathrm{H}), 3.54\left(\mathrm{~s}, 2 \mathrm{H}, \mathrm{CH}_{2}\right), 2.74(\mathrm{~s}, 2 \mathrm{H}), 2.29\left(\mathrm{~s}, 3 \mathrm{H}, \mathrm{CH}_{3}\right)$, $2.19\left(\mathrm{~s}, 6 \mathrm{H}, 2 \times \mathrm{CH}_{3}\right), 1.96(\mathrm{~s}, 2 \mathrm{H}), 1.45(\mathrm{~s}, 2 \mathrm{H}), 1.26(\mathrm{~s}, 2 \mathrm{H}) . \mathrm{IR}$ $\left(\mathrm{KBr}, \mathrm{cm}^{-1}\right): 3397\left(v_{\mathrm{NH}}\right), 2923\left(v_{\mathrm{CH} 3}^{\mathrm{as}}\right), 2228\left(v_{\mathrm{C}} \equiv_{\mathrm{N}}\right), 1564,1497$ $\left(v_{\mathrm{C}=\mathrm{N}}\right), 813\left(\omega_{\mathrm{C}=\mathrm{N}}\right)$. ESI-MS: $\mathrm{m} / \mathrm{z} 443.6(\mathrm{M}+1), 222.3((\mathrm{M}+2) / 2)$. $\mathrm{C}_{25} \mathrm{H}_{30} \mathrm{~N}_{8}$ [442.56].

4.1.5.9. $N^{2}$-mesityl- $N^{4}$-methyl-N6-(1-(pyridin-4-ylmethyl)piperidin-4-yl)-1,3,5-triazine-2,4,6-triamine (6b1). Pale yellow powder, yield: $67.7 \%$. Mp: $134-136{ }^{\circ} \mathrm{C} .{ }^{1} \mathrm{H}$ NMR $\left(\mathrm{CDCl}_{3}, \mathrm{ppm}\right) \delta$ : $8.54(\mathrm{~d}, 2 \mathrm{H}, J=3.6 \mathrm{~Hz}, \mathrm{PhH}), 6.90(\mathrm{~s}, 2 \mathrm{H}, \mathrm{PhH}), 6.23(\mathrm{~m}, 1 \mathrm{H}), 4.95$ (s, 2H), 3.49 (s, 2H, CH $\mathrm{CH}_{2}$ ) 2.94, (s, 3H, NCH3), 2.77 (s, 2H), 2.29 (s, $\left.3 \mathrm{H}, \mathrm{CH}_{3}\right), 2.20\left(\mathrm{~s}, 6 \mathrm{H}, 2 \times \mathrm{CH}_{3}\right), 2.04(\mathrm{~m}, 2 \mathrm{H}), 1.89(\mathrm{~m}, 2 \mathrm{H}), 1.50$ $(\mathrm{m}, 2 \mathrm{H}) .{ }^{13} \mathrm{C}$ NMR $\left(100 \mathrm{MHz}, \mathrm{CDCl}_{3}, \mathrm{ppm}\right) \delta: 18.59,20.99,27.52$, $32.28,52.38,61.58,123.79,128.67,136.12,147.88,149.79$. IR $\left(\mathrm{KBr}, \mathrm{cm}^{-1}\right): 3423\left(v_{\mathrm{NH}}\right), 3261\left(v_{\mathrm{NH}}\right), 2943\left(v_{\mathrm{CH} 3}^{\mathrm{as}}\right), 1560,1513\left(v_{\mathrm{C}=\mathrm{N}}\right)$, $812\left(\omega_{\mathrm{C}=\mathrm{N}}\right)$. ESI-MS: $m / z 433.7(\mathrm{M}+1), 217.6((\mathrm{M}+2) / 2) \cdot \mathrm{C}_{24} \mathrm{H}_{32} \mathrm{~N}_{8}$ [432.56].

4.1.5.10. ethyl 4-((4-(4-(mesitylamino)-6-(methylamino)-1,3,5triazin-2-ylamino)piperidin-1-yl)methyl)benzoate

(6b2). White powder, yield: $70.4 \%$. Mp: $127-129{ }^{\circ} \mathrm{C} .{ }^{1} \mathrm{H}$ NMR $\left(\mathrm{CDCl}_{3}, \mathrm{ppm}\right) \delta: 7.99(\mathrm{~d}, 2 \mathrm{H}, J=8.4 \mathrm{~Hz}, \mathrm{PhH}), 7.38(\mathrm{~d}, 2 \mathrm{H}$, $J=8.4 \mathrm{~Hz}, \mathrm{PhH}), 6.89(\mathrm{~s}, 2 \mathrm{H}, \mathrm{PhH}), 4.84(\mathrm{~s}, 2 \mathrm{H}), 4.37$ (q, 2H, $\left.J=7.2 \mathrm{~Hz}, \mathrm{CH}_{2}\right), 3.54\left(\mathrm{~s}, 2 \mathrm{H}, \mathrm{CH}_{2}\right), 2.91(\mathrm{~s}, 3 \mathrm{H}, \mathrm{NCH} 3), 2.76(\mathrm{~s}, 2 \mathrm{H})$, $2.28\left(\mathrm{~s}, 3 \mathrm{H}, \mathrm{CH}_{3}\right), 2.19\left(\mathrm{~s}, 6 \mathrm{H}, 2 \times \mathrm{CH}_{3}\right), 1.97(\mathrm{~m}, 2 \mathrm{H}), 1.46(\mathrm{~m}$, $2 \mathrm{H}), 1.39\left(\mathrm{t}, 3 \mathrm{H}, J=7.2 \mathrm{~Hz}, \mathrm{CH}_{3}\right)$. IR $\left(\mathrm{KBr}, \mathrm{cm}^{-1}\right): 3400\left(v_{\mathrm{NH}}\right), 3263$ $\left(v_{\mathrm{NH}}\right), 2941\left(v_{\mathrm{CH} 3}^{\mathrm{as}}\right), 1718\left(v_{\mathrm{C}=\mathrm{O}}\right), 1560,1513\left(v_{\mathrm{C}=\mathrm{N}}\right), 1275\left(v_{\mathrm{C}-\mathrm{O}-\mathrm{C}}^{\mathrm{as}}\right)$, $1106\left(v_{\mathrm{C}-\mathrm{O}-\mathrm{C}}^{\mathrm{as}}\right), 812\left(\omega_{\mathrm{C}=\mathrm{N}}\right)$. ESI-MS: $m / z 504.6(\mathrm{M}+1), \mathrm{C}_{28} \mathrm{H}_{37} \mathrm{~N}_{7} \mathrm{O}_{2}$ [503.64].

4.1.5.11. 4-((4-(4-(mesitylamino)-6-(methylamino)-1,3,5-triazin-2-ylamino)piperidin-1-yl)methyl)benzamide

(6b3). White powder, yield: $66.7 \%$. Decomposed at $237^{\circ} \mathrm{C} .{ }^{1} \mathrm{H}$ NMR (DMSO- $\left.d_{6}, \mathrm{ppm}\right) \delta$ : $7.92(\mathrm{~s}, 2 \mathrm{H}, \mathrm{PhH}), 7.82(\mathrm{~s}, 2 \mathrm{H}), 7.33(\mathrm{~d}, 3 \mathrm{H}$,
$J=23.4 \mathrm{~Hz}), 6.82(\mathrm{~s}, 2 \mathrm{H}, \mathrm{PhH}), 6.53(\mathrm{~m}, 1 \mathrm{H}), 3.48(\mathrm{~d}, 2 \mathrm{H}, J=25.2 \mathrm{~Hz})$ $2.74(\mathrm{~s}, 3 \mathrm{H}, \mathrm{NCH} 3), 2.60(\mathrm{~d}, 2 \mathrm{H}, J=9.0 \mathrm{~Hz}), 2.20\left(\mathrm{~s}, 3 \mathrm{H}, \mathrm{CH}_{3}\right), 2.07(\mathrm{~s}$ $\left.6 \mathrm{H}, 2 \times \mathrm{CH}_{3}\right), 1.91-1.99(\mathrm{~m}, 2 \mathrm{H}), 1.66-1.77(\mathrm{~m}, 2 \mathrm{H}), 1.40-1.50(\mathrm{~m}$, $2 \mathrm{H}) .{ }^{13} \mathrm{C}$ NMR $\left(100 \mathrm{MHz}\right.$, DMSO- $\left.d_{6}, \mathrm{ppm}\right) \delta: 18.81,20.94,27.59$, $32.23,47.31,52.81,62.23,127.86,128.51,128.91,133.43,134.59$, 135.01, 136.33, 142.52, 165.66, 166.90, 168.31. IR $\left(\mathrm{KBr}, \mathrm{cm}^{-1}\right)$ : $3402\left(v_{\mathrm{NH}}\right), 3271\left(v_{\mathrm{NH}}\right), 2923\left(v_{\mathrm{CH} 3}^{\mathrm{as}}\right), 1674(v \mathrm{c}=0), 1613\left(\beta_{\mathrm{NH}}\right)$, 1556, $1516\left(v_{\mathrm{C}=\mathrm{N}}\right), 812\left(\omega_{\mathrm{C}=\mathrm{N}}\right)$. ESI-MS: $m / z 475.5(\mathrm{M}+1)$, $\mathrm{C}_{26} \mathrm{H}_{34} \mathrm{~N}_{8} \mathrm{O}$ [474.60].

4.1.5.12. 4-((4-(4-(mesitylamino)-6-(methylamino)-1,3,5-triazin-2-ylamino)piperidin-1-yl)methyl)benzenesulfonamide

(6b4). White powder, yield: $68.3 \%$ Mp: $170-172{ }^{\circ} \mathrm{C} .{ }^{1} \mathrm{H}$ NMR $\left(\mathrm{CDCl}_{3}, \mathrm{ppm}\right) \delta: 7.79(\mathrm{~d}, 2 \mathrm{H}, J=7.2 \mathrm{~Hz}, \mathrm{PhH}), 7.50$ (d, $2 \mathrm{H}$, $J=7.8 \mathrm{~Hz}, \mathrm{PhH}), 6.79(\mathrm{~s}, 2 \mathrm{H}, \mathrm{PhH}), 5.15\left(\mathrm{~s}, 2 \mathrm{H}, \mathrm{NH}_{2}\right), 4.92(\mathrm{~s}, 2 \mathrm{H})$, $3.88(\mathrm{~m}, 1 \mathrm{H}), 3.55\left(\mathrm{~s}, 2 \mathrm{H}, \mathrm{CH}_{2}\right), 2.91(\mathrm{~s}, 3 \mathrm{H}, \mathrm{NCH} 3), 2.76(\mathrm{~s}, 2 \mathrm{H})$, $2.25\left(\mathrm{~s}, 3 \mathrm{H}, \mathrm{CH}_{3}\right), 2.12\left(\mathrm{~s}, 6 \mathrm{H}, 2 \times \mathrm{CH}_{3}\right), 1.82-2.04(\mathrm{~m}, 5 \mathrm{H}), 1.48$ $(\mathrm{m}, 2 \mathrm{H}) . \mathrm{IR}\left(\mathrm{KBr}, \mathrm{cm}^{-1}\right)$ : $3382\left(v_{\mathrm{NH}}\right), 2942\left(v_{\mathrm{CH} 3}^{\mathrm{as}}\right), 1571,1494\left(v_{\mathrm{C}=\mathrm{N}}\right)$, $1371\left(v_{\mathrm{O}}^{\mathrm{as}} \mathrm{S}_{-0}\right), 1160\left(v_{\mathrm{O}=\mathrm{S}=\mathrm{O}}\right), 1097\left(v_{\mathrm{S}=\mathrm{O}}\right), 811\left(\omega_{\mathrm{C}=\mathrm{N}}\right)$. ESI-MS: $\mathrm{m} /$ z $511.7(\mathrm{M}+1) \cdot \mathrm{C}_{25} \mathrm{H}_{34} \mathrm{~N}_{8} \mathrm{O}_{2} \mathrm{~S}$ [510.65].

4.1.5.13. $\quad N^{2}$-mesityl- $N^{4}$-methyl-N6-(1-(4-(methylsulfonyl)benzyl)piperidin-4-yl)-1,3,5-triazine-2,4,6-triamine

(6b5). White powder, yield: $71.4 \%$. Mp: $125-127{ }^{\circ} \mathrm{C} .{ }^{1} \mathrm{H}$ NMR $\left(\mathrm{CDCl}_{3}, \mathrm{ppm}\right) \delta: 7.88(\mathrm{~d}, 2 \mathrm{H}, J=7.8 \mathrm{~Hz}, \mathrm{PhH}), 7.53$ (d, $2 \mathrm{H}$, $J=7.2 \mathrm{~Hz}, \mathrm{PhH}), 6.89(\mathrm{~s}, 2 \mathrm{H}, \mathrm{PhH}), 4.86(\mathrm{~s}, 2 \mathrm{H}), 3.90(\mathrm{~m}, 1 \mathrm{H}), 3.57$ $\left(\mathrm{s}, 2 \mathrm{H}, \mathrm{CH}_{2}\right), 3.05\left(\mathrm{~s}, 3 \mathrm{H}, \mathrm{CH}_{3}\right), 2.94(\mathrm{~s}, 3 \mathrm{H}, \mathrm{NCH}), 2.76(\mathrm{~s}, 2 \mathrm{H})$, $2.28\left(\mathrm{~s}, 3 \mathrm{H}, \mathrm{CH}_{3}\right), 2.19\left(\mathrm{~s}, 6 \mathrm{H}, 2 \times \mathrm{CH}_{3}\right), 1.90-2.09(\mathrm{~m}, 3 \mathrm{H}), 1.50$ $(\mathrm{m}, 2 \mathrm{H}) . \mathrm{IR}\left(\mathrm{KBr}, \mathrm{cm}^{-1}\right): 3394\left(v_{\mathrm{NH}}\right), 3263\left(v_{\mathrm{NH}}\right), 2922\left(v_{\mathrm{CH} 3}^{\mathrm{as}}\right)$, 1570, $1513\left(v_{\mathrm{C}=\mathrm{N}}\right), 1371\left(v_{\mathrm{O}}^{\mathrm{as}} \mathrm{S}_{=}\right), 1150\left(v_{\mathrm{O}=\mathrm{S}=0}\right), 1089\left(v_{\mathrm{S}=0}\right)$, $812\left(\omega_{\mathrm{C}=\mathrm{N}}\right)$. ESI-MS: $m / z$ 510.6 $(\mathrm{M}+1) . \mathrm{C}_{26} \mathrm{H}_{35} \mathrm{~N}_{7} \mathrm{O}_{2} \mathrm{~S}$ [509.67].

4.1.5.14. $\quad N^{2}$-mesityl-6-methoxy- $N^{4}$-(1-(pyridin-4-ylmethyl) piperidin-4-yl)-1,3,5-triazine-2,4-diamine (6c1). Pale yellow powder, yield: $66.9 \%$. Mp: $122-124{ }^{\circ} \mathrm{C} .{ }^{1} \mathrm{H} \mathrm{NMR}\left(\mathrm{CDCl}_{3}, \mathrm{ppm}\right)$ $\delta: 8.54(\mathrm{~s}, 2 \mathrm{H}, \mathrm{PhH}), 7.53(\mathrm{~s}, 2 \mathrm{H}, \mathrm{PhH}), 6.90(\mathrm{~d}, 2 \mathrm{H}, J=24 \mathrm{~Hz}$, $\mathrm{PhH}), 6.23(\mathrm{~m}, 1 \mathrm{H}), 5.06(\mathrm{~m}, 1 \mathrm{H}), 3.93\left(\mathrm{~s}, 3 \mathrm{H}, \mathrm{OCH}_{3}\right), 3.71(\mathrm{~s}, 1 \mathrm{H})$, $3.50\left(\mathrm{~s}, 2 \mathrm{H}, \mathrm{CH}_{2}\right), 2.78(\mathrm{~s}, 2 \mathrm{H}), 2.29\left(\mathrm{~s}, 3 \mathrm{H}, \mathrm{CH}_{3}\right), 2.19(\mathrm{~s}, 6 \mathrm{H}$, $\left.2 \times \mathrm{CH}_{3}\right), 1.98(\mathrm{~m}, 2 \mathrm{H}), 1.80(\mathrm{~m}, 2 \mathrm{H}), 1.49(\mathrm{~m}, 2 \mathrm{H}) .{ }^{13} \mathrm{C}$ NMR $\left(100 \mathrm{MHz}, \mathrm{DMSO}-d_{6}, \mathrm{ppm}\right) \delta$ : $18.10,20.41,31.30,47.30,52.24$, $53.09,60.69,123.55,128.00,128.15,133.29,135.57,147.68$, 149.40, 166.03, 166.44, 170.58. IR $\left(\mathrm{KBr}, \mathrm{cm}^{-1}\right): 3392\left(v_{\mathrm{NH}}\right), 3249$ $\left(v_{\mathrm{NH}}\right), 2948\left(v_{\mathrm{CH} 3}^{\mathrm{as}}\right), 1577,1499\left(v_{\mathrm{C}=\mathrm{N}}\right), 1371\left(v_{=}^{\mathrm{as}}-\mathrm{O}-\mathrm{C}\right), 815$ $\left(\omega_{\mathrm{C}=\mathrm{N}}\right)$. ESI-MS: m/z $434.7(\mathrm{M}+1), 218.1((\mathrm{M}+2) / 2) \cdot \mathrm{C}_{24} \mathrm{H}_{31} \mathrm{~N}_{7} \mathrm{O}$ [433.55].

4.1.5.15. ethyl 4-((4-(4-(mesitylamino)-6-methoxy-1,3,5-triazin2-ylamino)piperidin-1-yl)methyl)benzoate (6c2). White powder, yield: $69.8 \%$ Mp: $142-144{ }^{\circ} \mathrm{C} .{ }^{1} \mathrm{H}$ NMR $\left(\mathrm{CDCl}_{3}, \mathrm{ppm}\right) \delta$ : 8.00 (s, 2H, PhH), 7.40 (s, 2H, PhH), 6.90 (d, $2 \mathrm{H}, J=22.8 \mathrm{~Hz}, \mathrm{PhH})$, $6.29(\mathrm{~m}, 1 \mathrm{H}), 5.05(\mathrm{~m}, 1 \mathrm{H}), 4.37\left(\mathrm{q}, 2 \mathrm{H}, J=6.6 \mathrm{~Hz}, \mathrm{CH}_{2}\right), 3.92(\mathrm{~s}$, $\left.3 \mathrm{H}, \mathrm{OCH}_{3}\right), 3.71(\mathrm{~s}, 1 \mathrm{H}), 3.56\left(\mathrm{~s}, 2 \mathrm{H}, \mathrm{CH}_{2}\right), 2.79(\mathrm{~s}, 2 \mathrm{H}), 2.29(\mathrm{~s}, 3 \mathrm{H}$, $\left.\mathrm{CH}_{3}\right), 2.19\left(\mathrm{~s}, 6 \mathrm{H}, 2 \times \mathrm{CH}_{3}\right), 1.97(\mathrm{~m}, 3 \mathrm{H}), 1.43(\mathrm{~m}, 2 \mathrm{H}), 1.39(\mathrm{t}$, $\left.3 \mathrm{H}, J=6.0 \mathrm{~Hz}, \mathrm{CH}_{3}\right)$. IR $\left(\mathrm{KBr}, \mathrm{cm}^{-1}\right): 3371\left(v_{\mathrm{NH}}\right), 3253\left(v_{\mathrm{NH}}\right), 2949$ $\left(v_{\mathrm{CH} 3}^{\mathrm{as}}\right), 1719\left(v_{\mathrm{C}=\mathrm{O}}\right), 1575,1499\left(v_{\mathrm{C}=\mathrm{N}}\right), 1369\left(v_{=\mathrm{C}}^{\mathrm{as}}-\mathrm{O}-\mathrm{C}\right), 1275$ $\left(v_{\mathrm{C}-\mathrm{O}-\mathrm{C}}^{\mathrm{as}}\right), 1106\left(v_{\mathrm{C}-\mathrm{O}-\mathrm{C}}^{\mathrm{s}}\right), 815\left(\omega_{\mathrm{C}=\mathrm{N}}\right)$. ESI-MS: $m \overline{\bar{l}} \mathrm{C}-\overline{5} 05.6(\mathrm{M}+1)$. $\mathrm{C}_{28} \mathrm{H}_{36} \mathrm{~N}_{6} \mathrm{O}_{3}$ [504.62].

4.1.5.16. 4-((4-(4-(mesitylamino)-6-methoxy-1,3,5-triazin-2ylamino)piperidin-1-yl)methyl)benzamide (6c3). White powder, yield: $72.4 \%$. Mp: $155-157{ }^{\circ} \mathrm{C} .{ }^{1} \mathrm{H}$ NMR $\left(\mathrm{CDCl}_{3}, \mathrm{ppm}\right) \delta$ : 7.73 (d, 2H, $J=7.8 \mathrm{~Hz}, \mathrm{PhH}$ ), 7.39 (d, 2H, $J=6.6 \mathrm{~Hz}, \mathrm{PhH}), 6.90$ (d, $2 \mathrm{H}, J=29.4 \mathrm{~Hz}, \mathrm{PhH}), 5.95\left(\mathrm{~s}, 2 \mathrm{H}, \mathrm{NH}_{2}\right), 3.92\left(\mathrm{~s}, 3 \mathrm{H}, \mathrm{OCH}_{3}\right), 3.71$ (s, $1 \mathrm{H}), 3.53\left(\mathrm{~s}, 2 \mathrm{H}, \mathrm{CH}_{2}\right), 2.78(\mathrm{~s}, 2 \mathrm{H}), 2.30\left(\mathrm{~s}, 3 \mathrm{H}, \mathrm{CH}_{3}\right), 2.20$ (s, $\left.6 \mathrm{H}, 2 \times \mathrm{CH}_{3}\right), 1.96(\mathrm{~m}, 2 \mathrm{H}), 1.77(\mathrm{~s}, 2 \mathrm{H}), 1.48(\mathrm{~m}, 2 \mathrm{H}) .{ }^{13} \mathrm{C} \mathrm{NMR}$ $\left(100 \mathrm{MHz}, \mathrm{DMSO}-d_{6}, \mathrm{ppm}\right) \delta$ : 18.10, 20.41, 31.34, 47.42, 52.21, 
$53.09,61.65,127.29,128.00,128.15,128.31,132.87,133.29$, $135.57,141.95,166.03,166.43,167.69,170.58$. IR $\left(\mathrm{KBr}, \mathrm{cm}^{-1}\right)$ : $3255\left(v_{\mathrm{NH}}\right), 2923\left(v_{\mathrm{CH} 3}^{\text {as }}\right), 1672\left(v_{\mathrm{C}=\mathrm{O}}\right), 1575,1498\left(v_{\mathrm{C}=\mathrm{N}}\right), 1373$ $\left(v^{\text {as }} \mathrm{C}-\mathrm{O}-\mathrm{C}\right), 814\left(\omega_{\mathrm{C}=\mathrm{N}}\right)$. ESI-MS: $m / z 476.4(\mathrm{M}+1) \cdot \mathrm{C}_{26} \mathrm{H}_{33} \mathrm{~N}_{7} \mathrm{O}_{2}$

\subsubsection{4-((4-(4-(mesitylamino)-6-methoxy-1,3,5-triazin-2- ylamino)piperidin-1-yl)methyl)benzenesulfonamide}

(6c4). White powder, yield: $71.1 \%$ Mp: $160-162{ }^{\circ} \mathrm{C} .{ }^{1} \mathrm{H}$ NMR $\left(\mathrm{CDCl}_{3}, \mathrm{ppm}\right) \delta: 7.81(\mathrm{~d}, 2 \mathrm{H}, J=7.2 \mathrm{~Hz}, \mathrm{PhH}), 7.46$ (d, $2 \mathrm{H}$, $J=7.2 \mathrm{~Hz}, \mathrm{PhH}), 6.84(\mathrm{~d}, 2 \mathrm{H}, J=34.8 \mathrm{~Hz}, \mathrm{PhH}), 6.35(\mathrm{~m}, 1 \mathrm{H}), 5.16$ $\left(\mathrm{s}, 2 \mathrm{H}, \mathrm{NH}_{2}\right), 3.91\left(\mathrm{~s}, 3 \mathrm{H}, \mathrm{OCH}_{3}\right), 3.71(\mathrm{~s}, 1 \mathrm{H}), 3.55\left(\mathrm{~s}, 2 \mathrm{H}, \mathrm{CH}_{2}\right)$, $2.78(\mathrm{~s}, 2 \mathrm{H}), 2.25\left(\mathrm{~s}, 3 \mathrm{H}, \mathrm{CH}_{3}\right), 2.13\left(\mathrm{~s}, 6 \mathrm{H}, 2 \times \mathrm{CH}_{3}\right), 1.97(\mathrm{~m}, 2 \mathrm{H})$, $1.84(\mathrm{~m}, 2 \mathrm{H}), 1.49(\mathrm{~m}, 2 \mathrm{H}) . \mathrm{IR}\left(\mathrm{KBr}, \mathrm{cm}^{-1}\right): 3350\left(v_{\mathrm{NH}}\right), 2924$ $\left(v_{\mathrm{CH} 3}^{\text {as }}\right), 1580,1400\left(v_{\mathrm{C}=\mathrm{N}}\right), 1385\left(v_{\mathrm{O}=\mathrm{S}=\mathrm{O}}^{\mathrm{as}}\right), 1161\left(v_{\mathrm{O}=\mathrm{S}=\mathrm{O}}\right), 1098$ $\left(v_{\mathrm{S}=\mathrm{O}}\right), 814\left(\omega_{\mathrm{C}=\mathrm{N}}\right)$. ESI-MS: $m / z=512.7 \quad(\mathrm{M}+1) . \quad \mathrm{C}_{25} \mathrm{H}_{33} \mathrm{~N}_{7} \mathrm{O}_{3} \mathrm{~S}$ [511.64].

\subsubsection{8. $\quad N^{2}$-mesityl-6-methoxy- $N^{4}$-(1-(4-(methylsulfonyl) benzyl)piperidin-4-yl)-1,3,5-triazine-2,4-diamine}

(6c5). White powder, yield: $72.0 \%$ Mp: $121-123{ }^{\circ} \mathrm{C} .{ }^{1} \mathrm{H}$ NMR $\left(\mathrm{CDCl}_{3}, \mathrm{ppm}\right) \delta: 7.88(\mathrm{~d}, 2 \mathrm{H}, J=7.2 \mathrm{~Hz}, \mathrm{PhH}), 7.53$ (d, $2 \mathrm{H}$, $J=7.2 \mathrm{~Hz}, \mathrm{PhH}$ ), 6.90 (d, 2H, $J=22.8 \mathrm{~Hz}, \mathrm{PhH}), 3.93\left(\mathrm{~s}, 3 \mathrm{H}, \mathrm{OCH}_{3}\right)$, $3.71(\mathrm{~s}, 1 \mathrm{H}), 3.57\left(\mathrm{~s}, 2 \mathrm{H}, \mathrm{CH}_{2}\right), 3.05\left(\mathrm{~s}, 3 \mathrm{H}, \mathrm{CH}_{3}\right), 2.76(\mathrm{~s}, 2 \mathrm{H}), 2.29$ (s, 3H, $\left.\mathrm{CH}_{3}\right), 2.19\left(\mathrm{~s}, 6 \mathrm{H}, 2 \times \mathrm{CH}_{3}\right), 1.98(\mathrm{~m}, 2 \mathrm{H}), 1.68(\mathrm{~m}, 2 \mathrm{H})$, $1.46(\mathrm{~m}, 2 \mathrm{H})$. IR $\left(\mathrm{KBr}, \mathrm{cm}^{-1}\right): 3365\left(v_{\mathrm{NH}}\right), 3257\left(v_{\mathrm{NH}}\right), 2923\left(v_{\mathrm{CH} 3}^{\mathrm{as}}\right)$, 1578, $1498\left(v_{\mathrm{C}=\mathrm{N}}\right), 1384\left(v_{\mathrm{O}}^{\text {as }} \mathrm{S}=\mathrm{O}\right), 1150\left(v_{\mathrm{O}=\mathrm{S}=\mathrm{O}}\right), 1089\left(v_{\mathrm{S}=\mathrm{O}}\right)$, $815\left(\omega_{\mathrm{C}=\mathrm{N}}\right)$. ESI-MS: $m / z 511.6(\mathrm{M}+1) . \mathrm{C}_{26} \mathrm{H}_{34} \mathrm{~N}_{6} \mathrm{O}_{3} \mathrm{~S}$ [510.65].

\subsection{In vitro anti-HIV activity assays}

Evaluation of the antiviral activity of the compounds against HIV-1 strain IIIB and HIV-2 strain (ROD) in MT-4 cells was performed using the MTT assay as previously described. ${ }^{24}$ Stock solutions ( $10 \times$ final concentration) of test compounds were added in $25-\mu \mathrm{L}$ volumes to two series of triplicate wells so as to allow simultaneous evaluation of their effects on mock- and HIV-infected cells at the beginning of each experiment. Serial fivefold dilutions of test compounds were made directly in flat-bottomed 96-well microtiter trays using a Biomek 3000 robot (Beckman instruments, Fullerton, CA). Untreated control HIV- and mock-infected cell samples were included for each sample.

HIV-1(IIIB) $)^{30}$ or HIV-2 (ROD) $)^{31}$ stock $(50 \mu \mathrm{L})$ at $100-300$ CCID50 (cell culture infectious dose) or culture medium was added to either the infected or mock-infected wells of the microtiter tray. Mock-infected cells were used to evaluate the effect of test compound on uninfected cells in order to assess the cytotoxicity of the test compound. Exponentially growing MT-4 cells ${ }^{32}$ were centrifuged for $5 \mathrm{~min}$ at $1000 \mathrm{rpm}$ and the supernatant was discarded. The MT- 4 cells were resuspended at $6 \times 10^{5}$ cells $/ \mathrm{mL}$, and $50-\mu \mathrm{L}$ volumes were transferred to the microtiter tray wells. Five days after infection, the viability of mock- and HIV-infected cells was examined spectrophotometrically by the MTT assay.

The MTT assay is based on the reduction of yellow colored 3(4,5-dimethylthiazol-2-yl)-2,5-diphenyltetrazolium bromide (MTT) (Acros Organics, Geel, Belgium) by mitochondrial dehydrogenase of metabolically active cells to a blue-purple formazan that can be measured spectrophotometrically. The absorbances were read in an eight-channel computer-controlled photometer (Multiscan Ascent Reader, Labsystems, Helsinki, Finland), at two wavelengths (540 and $690 \mathrm{~nm}$ ). All data were calculated using the median OD (optical density) value of tree wells. The $50 \%$ cytotoxic concentration $\left(\mathrm{CC}_{50}\right)$ was defined as the concentration of the test compound that reduced the absorbance (OD540) of the mock-infected control sample by $50 \%$. The concentration achieving $50 \%$ protection from the cytopathic effect of the virus in infected cells was defined as the $50 \%$ effective concentration $\left(\mathrm{EC}_{50}\right)$.

\section{Acknowledgments}

The financial support from the National Natural Science Foundation of China (NSFC Nos. 81102320, 30873133, 30772629, 30371686), Key Project of NSFC for International Cooperation (No. 30910103908), Research Fund for the Doctoral Program of Higher Education of China (Nos. 20110131130005, 20110131120037), Independent Innovation Foundation of Shandong University (IIFSDU, No. 2010GN044), Shandong Postdoctoral Innovation Science Research Special Program (No.201002023), China Postdoctoral Science Foundation funded project (No.20100481282) and KU Leuven (GOA 10/014) is gratefully acknowledged. We thank K. Erven, K. Uyttersprot and C. Heens for technical assistance with the HIV assays.

\section{References and notes}

1. Hirschel, B.; Francioli, P. N. Eng. J. Med. 1998, 338, 906

2. De Clercq, E. Curr. Med. Chem. 2001, 8, 1543.

3. Chen, X. W.; Zhan, P.; Li, D. Y.; De Clercq, E.; Liu, X. Y. Curr. Med. Chem. 2011, 18, 359.

4. Miller, C. D.; Crain, J.; Tran, B.; Patel, N. Drugs Today (Barc) 2011, 47, 5.

5. Feng, X. Q.; Liang, Y. H.; Zeng, Z. S.; Chen, F. E.; Balzarini, J.; Pannecouque, C.; De Clercq, E. ChemMedChem 2009, 4, 219.

6. Liang, Y. H.; Feng, X. Q.; Zeng, Z. S.; Chen, F. E.; Balzarini, J.; Pannecouque, C.; De Clercq, E. ChemMedChem 2009, 4, 1537.

7. Liang, Y. H.; He, Q. Q.; Zeng, Z. S.; Liu, Z. Q.; Feng, X. Q.; Chen, F. E.; Balzarini, J.; Pannecouque, C.; Clercq, E. D. Bioorg. Med. Chem. 2010, 18, 4601.

8. Feng, X. Q.; Zeng, Z. S.; Liang, Y. H.; Chen, F. E.; Pannecouque, C.; Balzarini, J.; De Clercq, E. Bioorg. Med. Chem. 2010, 18, 2370.

9. Zeng, Z. S.; Liang, Y. H.; Feng, X. Q.; Chen, F. E.; Pannecouque, C.; Balzarini, J.; De Clercq, E. ChemMedChem 2010, 5, 837.

10. Gu, S. X.; He, Q. Q.; Yang, S. Q.; Ma, X. D.; Chen, F. E.; De Clercq, E.; Balzarini, J.; Pannecouque, C. Bioorg. Med. Chem. 2011, 19, 5117.

11. Heeres, J.; de Jonge, M. R.; Koymans, L. M.; Daeyaert, F. F.; Vinkers, M.; Van Aken, K. J.; Arnold, E.; Das, K.; Kilonda, A.; Hoornaert, G. J.; Compernolle, F.; Cegla, M.; Azzam, R. A.; Andries, K.; de Bethune, M. P.; Azijn, H.; Pauwels, R.; Lewi, P. J.; Janssen, P. A. J. Med. Chem. 2005, 48, 1910.

12. Tian, X.; Qin, B.; Lu, H.; Lai, W.; Jiang, S.; Lee, K. H.; Chen, C. H.; Xie, L. Bioorg. Med. Chem. Lett. 2009, 19, 5482.

13. Tian, X.; Qin, B.; Wu, Z.; Wang, X.; Lu, H.; Morris-Natschke, S. L.; Chen, C. H.; Jiang, S.; Lee, K. H.; Xie, L. J. Med. Chem. 2010, 53, 8287.

14. Qin, B.; Jiang, X.; Lu, H.; Tian, X.; Barbault, F.; Huang, L.; Qian, K.; Chen, C. H.; Huang, R.; Jiang, S.; Lee, K. H.; Xie, L. J. Med. Chem. 2010, 53, 4906.

15. Kertesz, D. J.; Brotherton-Pleiss, C.; Yang, M. M.; Wang, Z. G.; Lin, X. F.; Oiu, Z X.; Hirschfeld, D. R.; Gleason, S.; Mirzadegan, T.; Dunten, P. W.; Harris, S. F.; Villasenor, A. G.; Hang, J. Q.; Heilek, G. M.; Klumpp, K. Bioorg. Med. Chem. Lett. 2010, 20, 4215

16. Tang, G. Z.; Kertesz, D. J.; Yang, M. M.; Lin, X. F.; Wang, Z. G.; Li, W. T.; Qiu, Z. X.; Chen, J. L.; Mei, J. H.; Chen, L.; Mirzadegan, T.; Harris, S. F.; Villasenor, A. G.; Fretland, J.; Fitch, W. L.; Hang, J. Q.; Heilek, G.; Klumpp, K. Bioorg. Med. Chem. Lett. 2010, 20, 6020 .

17. Chen, X. W.; Zhan, P.; Pannecouque, C.; Balzarini, J.; De Clercq, E.; Liu, X. Y. Eur. J. Med. Chem. 2012, 51, 60.

18. Udier-Blagovic, M.; Tirado-Rives, J.; Jorgensen, W. L. J. Am. Chem. Soc. 2003, 125, 6016.

19. Ren, J.; Chamberlain, P. P.; Stamp, A.; Short, S. A.; Weaver, K. L.; Romines, K. R.; Hazen, R.; Freeman, A.; Ferris, R. G.; Andrews, C. W.; Boone, L.; Chan, J. H.; Stammers, D. K. J. Med. Chem. 2008, 51, 5000.

20. Zacharie, B.; Abbott, S. D.; Bienvenu, J. F.; Cameron, A. D.; Cloutier, J.; Duceppe, J. S.; Ezzitouni, A.; Fortin, D.; Houde, K.; Lauzon, C.; Moreau, N.; Perron, V.; Wilb, N.; Asselin, M.; Doucet, A.; Fafard, M. E.; Gaudreau, D.; Grouix, B.; SarraBournet, F.; St-Amant, N.; Gagnon, L.; Penney, C. L. J. Med. Chem. 2010, 53, 1138.

21. Leftheris, K.; Ahmed, G.; Chan, R.; Dyckman, A. J.; Hussain, Z.; Ho, K.; Hynes, J., Jr.; Letourneau, J.; Li, W.; Lin, S.; Metzger, A.; Moriarty, K. J.; Riviello, C.; Shimshock, Y.; Wen, J.; Wityak, J.; Wrobleski, S. T.; Wu, H.; Wu, J.; Desai, M.; Gillooly, K. M.; Lin, T. H.; Loo, D.; McIntyre, K. W.; Pitt, S.; Shen, D. R.; Shuster, D. J.; Zhang, R.; Diller, D.; Doweyko, A.; Sack, J.; Baldwin, J.; Barrish, J.; Dodd, J.; Henderson, I.; Kanner, S.; Schieven, G. L.; Webb, M. J. Med. Chem. 2004, 47, 6283

22. Wuest, J. D.; Lebel, O. Tetrahedron 2009, 65, 7393.

23. Pauwels, R.; Balzarini, J.; Baba, M.; Snoeck, R.; Schols, D.; Herdewijn, P.; Desmyter, J.: De Clercq, E. J. Virol. Methods 1988, 20, 309.

24. Pannecouque, C.; Daelemans, D.; De Clercq, E. Nat. Protoc. 2008, 3, 427.

25. Zhan, P.; Liu, X. Y.; Li, Z. Y.; Fang, Z. J.; Li, Z.; Wang, D. F.; Pannecouque, C.; De Clercq, E. Bioorg. Med. Chem. 2009, 17, 5920. 
26. Gu, S. X.; Yang, S. Q.; He, Q. Q.; Ma, X. D.; Chen, F. E.; Dai, H. F.; Clercq, E. D.; Balzarini, J.; Pannecouque, C. Bioorg. Med. Chem. 2011, 19, 7093.

27. D’Aquila, R. T.; Schapiro, J. M.; Brun-Vezinet, F.; Clotet, B.; Conway, B.; Demeter, L. M.; Grant, R. M.; Johnson, V. A.; Kuritzkes, D. R.; Loveday, C.; Shafer, R. W.; Richman, D. D. Top. HIV Med. 2003, 11, 92.

28. Romines, K. R.; Freeman, G. A.; Schaller, L. T.; Cowan, J. R.; Gonzales, S. S.; Tidwell, J. H.; Andrews, C. W., 3rd; Stammers, D. K.; Hazen, R. J.; Ferris, R. G.; Short, S. A.; Chan, J. H.; Boone, L. R. J. Med. Chem. 2006, 49, 727.
29. Zhang, Z.; Xu, W.; Koh, Y. H.; Shim, J. H.; Girardet, J. L.; Yeh, L. T.; Hamatake, R. K.; Hong, Z. Antimicrob. Agents Chemother. 2007, 51, 429.

30. Popovic, M.; Sarngadharan, M. G.; Read, E.; Gallo, R. Science 1984, 224, 497.

31. Clavel, F.; Guetard, D.; Brun-Vezinet, F.; Chamaret, S.; Rey, M. A.; SantosFerreira, M. O.; Laurent, A. G.; Dauguet, C.; Katlama, C.; Rouzioux, C., et al Science 1986, 233, 343.

32. Miyoshi, I.; Taguchi, H.; Kobonishi, I.; Yoshimoto, S.; Ohtsuki, Y.; Shiraishi, Y.; Akagi, T. Gann. Monogr. 1982, 28, 219. 